\title{
THE HOPPING DEAD: LATE CRETACEOUS FROGS FROM THE MIDDLE - LATE CAMPANIAN (JUDITHIAN) OF WESTERN NORTH AMERICA
}

\author{
JAMES D. GARDNER ${ }^{1 *}$, CORY M. REDMAN², RICHARD L. CIFELLI ${ }^{3}$ \\ ' Royal Tyrrell Museum of Palaeontology, Box 7500, Drumheller, Alberta, TOJ 0Y0, Canada; e-mail: james.gardner@gov.ab.ca. \\ 2 Des Moines University, Department of Anatomy, 3200 Grand Ave, Des Moines, lowa, 50312, USA; e-mail: corymredman@gmail.com. \\ ${ }^{3}$ Oklahoma Museum of Natural History, University of Oklahoma, 2401 Chautauqua Ave., Norman, Oklahoma, 73072, USA; e-mail: rlc@ou.edu. \\ corresponding author
}

Gardner, J. D., Redman, C. M., Cifelli, R. L. (2016): The hopping dead: Late Cretaceous frogs from the middle - late Campanian (Judithian) of western North America. - Fossil Imprint, 72(1-2): 78-107, Praha. ISSN 2533-4050 (print), ISSN 2533-4069 (on-line).

\begin{abstract}
The Mesozoic record for anurans (i.e., crown-clade frogs) in North America extends from the Early Jurassic to terminal Cretaceous. Here we review the record for middle - late Campanian (= Judithian North American Land Mammal Age and ca. 79-73 million years ago) anurans from the North American Western Interior. Judithian anuran fossils (mostly isolated bones) are known from dozens of localities in ten formations, distributed from southern Alberta and Saskatchewan, Canada, southwards into southern Texas, USA. Based largely on distinctive cranial bones, we recognize six or, perhaps, seven species: three named species (Scotiophryne pustulosa, Hensonbatrachus kermiti, and Tyrrellbatrachus brinkmani); three potentially diagnosable species (Theatonius n. sp. and two unnamed new genera and species); and one Scotiophryne-like species (cf. Scotiophryne sp.). On the basis of distinctive maxillae, we also recognize three broad groups of morphs, each of which likely contains multiple, as yet unrecognizable taxa. The familial affinities of those taxa and morphs are uncertain, due to the fragmentary nature of the available specimens. We provisionally recognize two geographic assemblages of Judithian anurans: a northern one encompassing Alberta, Canada and Montana, USA and a southern one encompassing Wyoming, Utah, and New Mexico, USA. The Judithian anuran record contains some species restricted to that interval and other taxa having longer temporal ranges and it documents the first appearances of edentulous anurans (T. brinkmani and Theatonius n. sp.) in the Northern Hemisphere.
\end{abstract}

Key words: Anura, Campanian, Cretaceous, fossils, North America, paleobiogeography

Received: May 20, 2016 | Accepted: July 14, 2016 | Issued: August 15, 2016

\section{Introduction}

Anurans (frogs and toads) are the most taxonomically diverse and widespread clade of living amphibians, comprising over 6600 extant and 100 fossil species and having occurrences on every continent, except Antarctica (e.g., Duellman and Trueb 1986, Sanchiz 1998, Roček 2013; see also Amphibian Species of the World: an Online Reference. Version 6.0 by D. R. Frost at http://research.amnh. org/herpetology/amphibia/index.html; accessed: 20 April 2016 and AmphibiaWeb, http://amphibiaweb.org/, accessed: 20 April 2016). Anurans have a modest fossil record extending back to the Early Jurassic (e.g., Sanchiz 1998, Roček and Rage 2000, Roček 2000, 2013). The most stratigraphically continuous record for anurans during the Late Cretaceous Epoch (ca. 100.5-66 million years ago, according to the time scale of Walker et al. 2013) occurs in the North American Western Interior (i.e., the region between the Rocky Mountains in the west and the Great Plains in the east, and from southern Canada into northern Mexico). In that region, anurans are known from dozens of localities, from the start of the Cenomanian through to the end of the
Maastrichtian (e.g., Estes 1964, Estes and Sanchiz 1982, Cifelli et al. 1999, Roček 2000, Gardner 2008, Roček et al. 2010, Gardner and DeMar 2013). Despite this geographically and temporally extensive record, the North American Late Cretaceous anuran record is hampered by most of the available fossils being isolated bones. This limitation is partially offset by the abundance of fossil anuran localities and specimens, the range of morphological variation exhibited by certain elements (e.g., maxillae and ilia), and the excellent preservation of some specimens. Although isolated anuran bones can be challenging to interpret, they are the major source of information about North American Late Cretaceous anurans and, with some caveats, have proven useful for recognizing taxonomic groups and species richness, for inferring broad evolutionary patterns (e.g., body sizes, tooth loss, iliac structure), and for demonstrating that anurans were a characteristic component of Late Cretaceous non-marine ecosystems on the continent (e.g., Estes 1964, 1969, Sahni 1972a, b, Fox 1976a, b, Estes and Sanchiz 1982, Brinkman 1990, Gardner 2008, Roček et al. 2010, Gardner and DeMar 2013). 


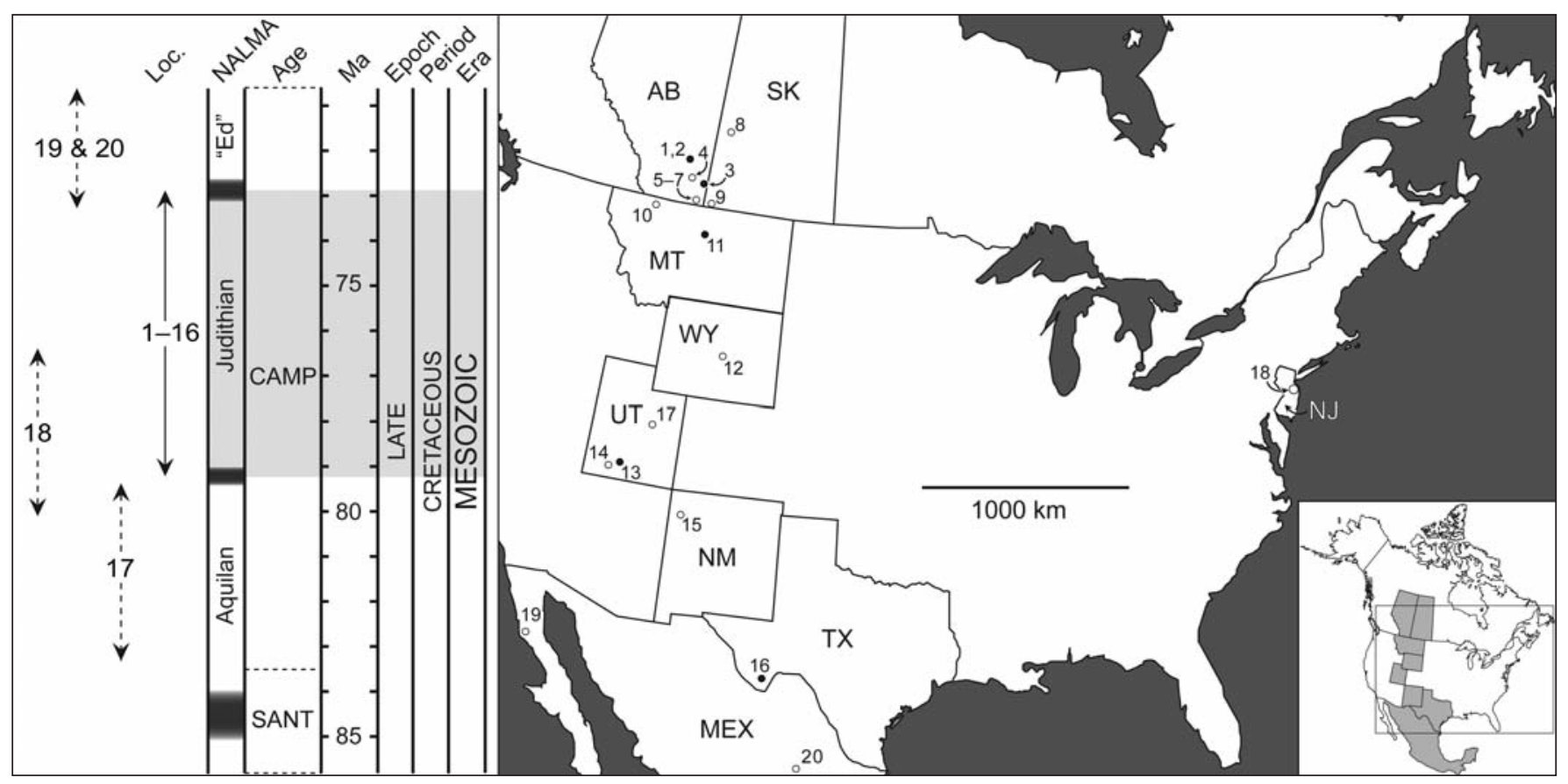

Text-fig. 1. Temporal and geographical distributions of anuran-bearing localities of middle - late Campanian (Judithian) age in North America. Inset map (lower right) shows portion of North American continent depicted in main map. Notes on time scale (left side): approximate time span for the Judithian North American Land Mammal Age (NALMA) is shaded; for simplicity localities are shown grouped together within the Judithian; thicker, fuzzy horizontal lines in NALMA column indicate approximate temporal gaps between NALMAs; other boundaries and absolute ages follow Walker et al. (2013). Notes on localities: localities of both definite Judithian age (localities 1-16) and four other localities highlighted in Discussion (localities 17-20) are depicted; positions of localities on main map are approximate; closed circles denote localities that have yielded specimens figured in this paper and open circles denote other localities. Abbreviations: AB, Alberta; CAMP, Campanian; "Ed", "Edmontonian"; Loc., Localities; Ma, millions of years ago; MEX, Mexico; MT, Montana; NALMA, North American Land Mammal Age; NJ, New Jersey; NM, New Mexico; SANT, Santonian; SK, Saskatchewan; TX, Texas; UT, Utah WY, Wyoming. Formations and localities are as follows: 1 - Dinosaur Park Formation: localities (including type locality for Tyrrellbatrachus brinkmani GARDNER, 2015) throughout vertical extent of formation in Dinosaur Provincial Park area, Alberta, Canada. 2 - Upper part of Oldman Formation: localities in Dinosaur Provincial Park area, Alberta, Canada. 3 - Upper part of Dinosaur Park Formation: Irvine locality (type locality for Hensonbatrachus kermiti GARDNER et BRINKMAN, 2015), Alberta, Canada. 4 - Upper part of Foremost Formation: SPS locality along Oldman River, Alberta, Canada. 5 - Oldman Formation: localities throughout vertical extent of formation along eastern portion of Milk River valley, Alberta, Canada. 6 - Upper part of Foremost Formation: localities in Pinhorn Ranch and Chin Coulee areas, along eastern portion and north of Milk River, Alberta, Canada. 7 - Upper part of Dinosaur Park Formation: localities in Onefour area, Alberta, Canada. 8 - Middle or upper part of Dinosaur Park Formation: Muddy Lake bonebed, near Unity, Saskatchewan, Canada. 9 - Formation uncertain (either Dinosaur Park Formation or Oldman Formation): Woodpile Creek, Saskatchewan, Canada. 10 - Middle part of Two Medicine Formation: MOR locality TM-088, Montana, USA. 11 - Upper Part of Judith River Formation: Clam Bank Hollow and University of Chicago vertebrate microfossil localities, Missouri River Valley, Montana, USA. 12 - Middle part of Mesaverde Formation: Barwin Quarry-Fales Rocks locality, Wyoming, USA. 13 - Kaiparowits Formation: localities on Kaiparowits Plateau, Utah, USA. 14 - Upper part of Wahweap Formation: localities on Kaiparowits and Paunsaugunt plateaus, Utah, USA; 15 - Upper part of Fruitland Formation: localities in San Juan Basin, New Mexico, USA. 16 Upper part of Aguja Formation: localities in Big Bend National Park area, Texas, USA. 17 - Blackhawk Formation: Meetinghouse Canyon, Utah, USA; probably early Campanian age (NALMA not reported). 18 - Marshalltown Formation: Ellisdale, New Jersey, USA; middle Campanian, possibly equivalent to Aquilan and Judithian NALMAs. 19 - El Gallo Formation: localities in Baja California, Mexico; late Campanian and probably "Edmontonian" equivalent. 20 - Cerro del Pueblo Formation: localities in La Parrita, Coahuila, Mexico; late Campanian and probably "Edmontonian" equivalent. Not shown is the Sandy Point area, southeastern Alberta (Oldman Formation), located east of Dinosaur Provincial Park and north of the Irvine locality (see Gardner and Brinkman 2015: fig. 2). Adapted from Gardner and DeMar (2013: figs 5-7).

In North America, Late Cretaceous anurans are best documented from the late Maastrichtian (ca. 69-66 million years ago), especially in Wyoming and Montana, USA, and also by additional occurrences elsewhere in the western USA and Canada (see reviews by Gardner 2008, Gardner and DeMar 2013). Four named anuran species have been recognized from that interval and region on the basis of isolated bones: Scotiophryne pustulosa ESTES, 1969;
Theatonius lancensis Fox, 1976b; Paradiscoglossus americanus ESTES et SANCHIZ, 1982; and Palaeobatrachus occidentalis ESTES et SANCHIZ, 1982. Also known are numerous examples of distinctive skull and postcranial bones, some of which likely pertain to additional, undescribed late Maastrichtian species (Estes 1964, 1969, Fox 1976b, Estes and Sanchiz 1982, Breithaupt 1982, 1985, Gardner 2008, Gardner and DeMar 2013, Mercier et al. 2014). 


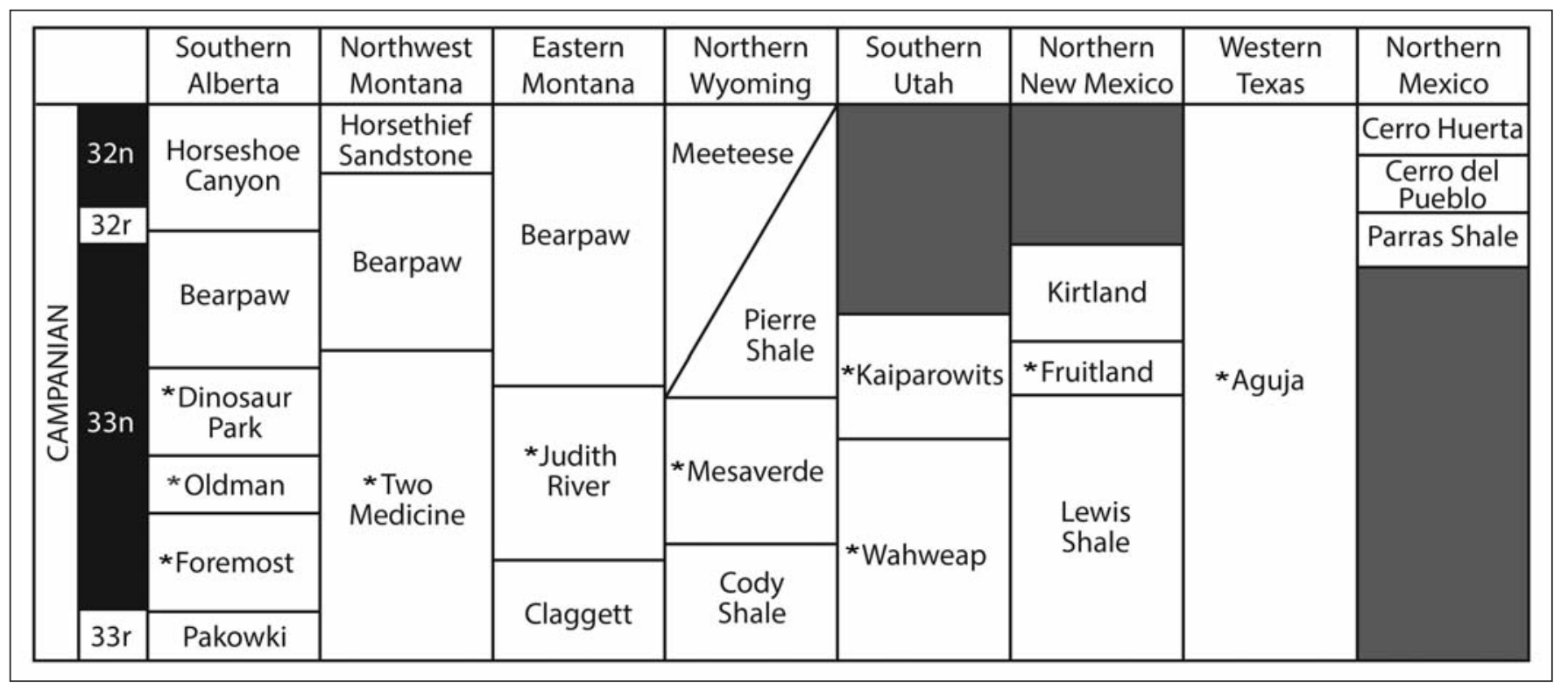

Text-fig. 2. Regional correlation chart for Campanian formations in the North American Western Interior showing relative stratigraphic relationships among the ten formations in the region that have yielded anuran fossils of middle - late Campanian (Judithian) age. Anuran-bearing formations marked with an asterisk (*). The younger (late Campanian - early Maastrichtian or "Edmontonian" in age) Horseshoe Canyon Formation in southern Alberta and Cerro del Pueblo Formation in northern Mexico also have yielded anuran fossils (see Gardner and DeMar 2013 and references therein). Chart compiled using data presented by Sampson and Loewen (2010), Jinnah (2013), and Roberts et al. (2013).

Setting aside limited records from the late Campanian early Maastrichtian (see Gardner and DeMar 2013 and references therein), the next oldest anuran assemblage in North America dates from the middle - late Campanian (= Judithian North American Land Mammal Age, see "Age and Geological Setting" below) or about 79-73 million years ago. The first evidence of anurans from that interval was in the form of isolated bones recovered by screen washing for fossil mammal jaws and teeth in the mid-1960s in the Judith River Formation of Montana, USA (Sahni 1968, 1972a, b) and the Oldman and Dinosaur Park formations (sensu Eberth 2005) of Alberta, Canada (Fox 1976a). Anurans are now known from 10 formations of unequivocal Judithian age in the Western Interior, at localities in southern Canada southwards into Texas, USA (e.g., Gardner and DeMar 2013 and references therein; Text-figs 1,2).

Historically, middle - late Campanian anuran assemblages in the Western Interior were considered impoverished relative to the better-studied, late Maastrichtian assemblages in the region. Most reports of middle - late Campanian anurans in the Western Interior were in the form of faunal lists and brief mentions or accounts in larger faunal studies, field trip guidebooks, conference abstracts, and unpublished graduate theses (e.g., Sahni 1968, 1972a, b, Fox 1976a, Armstrong-Ziegler 1978, 1980, Breithaupt 1985, Currie 1986, Tokaryk 1988, Brinkman 1990, Rowe et al. 1992, Peng et al. 1995, 2001, Eaton et al. 1999, Gardner 2000, 2005, Eberth et al. 2001, DeMar and Breithaupt 2006, 2008, Frampton 2006, Sankey 2006, Cullen et al. 2016). Several detailed descriptions of selected specimens and taxa have been presented (e.g., Roček et al. 2010, Gardner 2015, Gardner and Brinkman 2015) and anurans from that interval were included as part of a broader review of North American fossil lissamphibians (Gardner and DeMar 2013). Two new anuran genera and species (Hensonbatrachus kermiti GARDNER et BRINKMAN, 2015 and Tyrrellbatrachus brinkmani GARDNER, 2015) recently were described on the basis of isolated bones from the middle - late Campanian of Alberta, Canada. An earlier named taxon, Nezpercius dodsoni Blob, Carrano, Rogers, Forster et Espinoza, 2001, of the same age from Montana, USA, is no longer considered an anuran, because it was described on the basis of salamander ilia (Gardner et al. 2010). Farther to the south in the USA, the late Maastrichtian anurans Scotiophryne and Theatonius have been reported from localities of middle - late Campanian age in Wyoming, Utah, and New Mexico (Armstrong-Ziegler 1978, 1980, Breithaupt 1985, DeMar and Breithaupt 2006, 2008, Roček et al. 2010, Gardner and DeMar 2013). The existence of additional anuran taxa during the middle - late Campanian in the Western Interior is suggested by distinctive skull and postcranial bones at various localities (e.g., Sahni 1972b, Rowe et al. 1992, Gardner 2000, Roček et al. 2010, Gardner and DeMar 2013).

Here we review the record of middle - late Campanian anurans in the North American Western Interior, based on a survey of the literature and our examination of previously reported and new fossils. We describe and highlight specimens that (1) are new occurrences or new examples for previously recognized species and (2) belong to potentially diagnosable, but as yet unnamed species. Ours is an interim-style review. Certain specimens and taxa included in our review await more detailed study and formal description. Also, collections from several study areas deserve to be surveyed more systematically for lissamphibian fossils; that planned work is certain to reveal additional anuran specimens and taxa in addition to those reported here. 


\section{Age and Geological Setting}

Here we use both stages (e.g., Campanian) and North American Land Mammal Ages (NALMAs) for relative geological ages within the Western Interior. NALMAs are based on age-diagnostic, mammalian taxa from non-marine, Upper Cretaceous and Cenozoic deposits in the Western Interior (e.g., Woodburne 2004 and papers therein). Due to episodes of restricted terrigenous deposition in the Western Interior, Late Cretaceous NALMAs may be separated by gaps up to several millions of years in duration. From oldest to youngest, the four Late Cretaceous NALMAs and their stage equivalents are as follows (see recent treatments by Cifelli et al 2004, Kielan-Jaworowska et al. 2004): Aquilan (= late Santonian - early Campanian); Judithian (= middle late Campanian); "Edmontonian" (= late Campanian - early Maastrichtian); and Lancian (= late Maastrichtian). The anuran fossils and taxa documented in our review are from localities that correlate with the Judithian NALMA, which is about 5 or 6 million years in duration (cf. Weil 1999 vs. Cifelli et al. 2004) and from about 79-73 million years ago (estimated from the time scale of Walker et al. 2013).

Although a few of the anuran fossils included in our study were found by hand quarrying, the vast majority were recovered by surface collecting and screen washing of vertebrate microfossil localities (i.e., accumulations of small-sized bones, teeth, and scales) deposited in a mixture of fluvial, floodplain, and paludal (i.e., marshy) environments in the North American Western Interior, between the newly emergent Rocky Mountains to the west and the Cretaceous Interior Seaway to the east. The fossils come from localities in 10 formations in the Western Interior of southern Canada and the USA (Text-figs 1, 2). A recent review of the North American Mesozoic and Paleocene lissamphibian record reported anurans from nine of those formations (Gardner and DeMar 2013). Here we add the middle and upper portions of the Wahweap Formation in Utah, USA, to that inventory, because work by Jinnah (2013: fig. 4.3) indicates those portions of the formation correlate with the early Judithian. For more detailed information on Judithian anuran-bearing localities and their formations, see the following: Dinosaur Park, Oldman, and Foremost formations (Eberth 1990, 2005, Brinkman 1990, Eberth et al. 1990, Peng et al. 2001, Brinkman et al. 2004, Gardner and Brinkman 2015); Two Medicine Formation (Varricchio 2002); Judith River Formation (Sahni 1972b, Rogers and Brady 2010); Mesaverde Formation (Breithaupt 1985, DeMar and Breithaupt 2006, 2008); Kaiparowits and Wahweap formations (Eaton and Cifelli 1988, Roček et al. 2010, Gardner et al. 2013, Jinnah 2013, Roberts et al. 2013); Fruitland Formation (Armstrong-Ziegler 1980); and Aguja Formation (Rowe et al. 1992, Sankey 2006, 2008).

\section{Materials and Methods}

Except for an undescribed, articulated skeleton (see Gardner and DeMar 2016: fig. 2q) and disarticulated, but associated bones from the Two Medicine Formation of Montana, USA, the Judithian anuran record is limited to isolated and typically incomplete cranial and postcranial bones from metamorphosed individuals. Our review focuses on cranial bones, especially maxillae, because those are among the most commonly recovered anuran elements from Cretaceous localities in the Western Interior, they exhibit a range of distinctive morphologies, and cranial bones potentially can be associated with some confidence. Osteological terms generally follow Sanchiz (1998: figs 8-14) and Roček et al. (2010: fig. 3). We also follow Trueb (1973) and Fox (1976b) in using the term "pars facialis" for the dorsally directed flange extending the length of the maxilla above the lingually directed, shelf-like lamina horizontalis (= "pars palatinum" of some authors) and the ventrally directed and often tooth-bearing crista dentalis (= "pars dentalis" of some authors). Linear measurements are straight line values. Institutional abbreviations (Appendix 1) and an annotated list of taxa, specimens, and occurrences (Appendix 2) are presented at the end of this paper.

\section{Systematic Paleontology of Judithian Anurans}

\author{
Subclass Lissamphibia HAECKEL, 1866 \\ Order Salientia LAURENTI, 1768 \\ Crown-order Anura FisCHER [DE WALDHEIM], 1813 \\ Family(ies) Indeterminate
}

R e marks: Due to their fragmentary nature and lack of obvious synapomorphies or other diagnostically reliable features, none of the specimens and taxa reported below can be assigned with confidence to any anuran family.

\section{Scotiophryne pustulosa ESTES, 1969}

(Text-fig. 3a-k)

Material and occurrences: Maxilla and ilia from Mesaverde Formation, Wyoming, USA; maxillae, squamosals, frontoparietals, and fragmentary skull bones from Kaiparowits Formation, Utah, USA; ilia from Wahweap Formation, Utah, USA; and maxilla from Fruitland Formation, Utah, USA (Appendix 2). Also reported on the basis of isolated bones from older (Aptian - Albian and late Santonian - early Campanian) and younger (late Maastrichtian and early Paleocene) rock units in the Western Interior of USA and Canada and, outside of the Western Interior, in the Campanian of both Baja California, Mexico and New Jersey, USA (see "Remarks", below).

Description: Specimens figured here (Text-fig. $3 \mathrm{a}-\mathrm{k}$ ) are two incomplete maxillae, a fragmentary squamosal, and two fragmentary frontoparietals from the Kaiparowits Formation, Utah. Both maxillae (Text-fig. 3a-d) are from the right side and are broken anteriorly and posteriorly. Each preserves the middle and posterior portions of the suborbital region and varying amounts of the postorbital region. The processus pterygoideus is broken on both specimens. Neither maxilla has any intact teeth, however, OMNH 67105 (Text-fig. 3d, e: arrow), preserves a replacement tooth crown in situ and its posteriorly intact tooth row extends a short distance beyond the level of the broken base of the processus pterygoideus. These maxillae are from comparably-sized individuals and resemble similarly incomplete maxillae of the species previously reported by Roček et al. (2010: fig. 


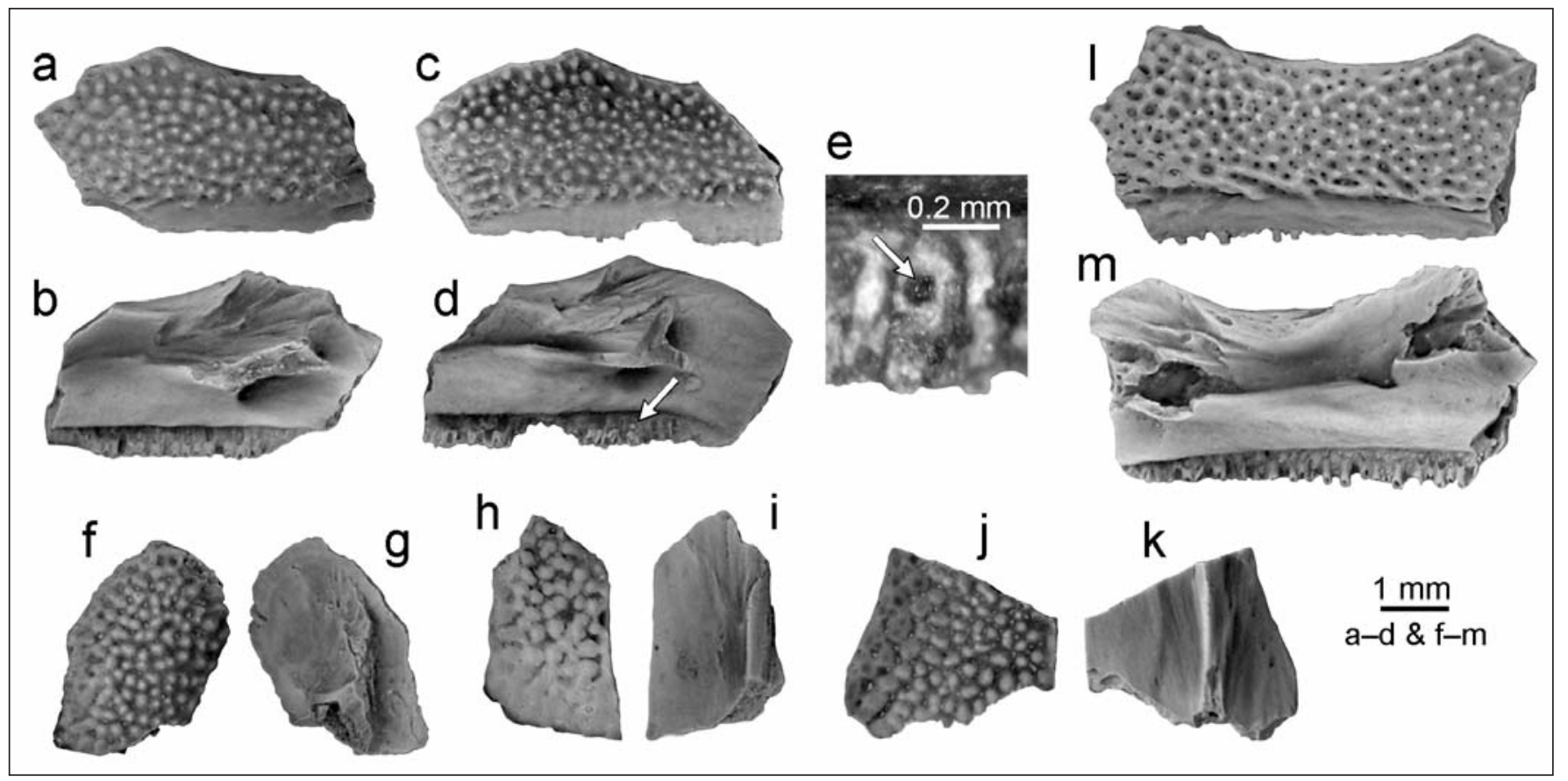

Text-fig. 3. Skull bones of Scotiophryne pustulosa EsTES, 1969 and cf. Scotiophryne sp. from the middle - late Campanian (Judithian) of Utah and Montana, USA. All images are photographs and most depict specimens lightly dusted with ammonium chloride to enhance details and texture. Images at different magnifications; see corresponding scale bars. a-k - Scotiophryne pustulosa Estes, 1969, all from Kaiparowits Formation, OMNH locality V9, Utah: a, b - incomplete right maxilla, OMNH 67093, in labial (a) and lingual (b) views; $\mathrm{c}-\mathrm{e}$ - incomplete right maxilla, OMNH 67105, entire specimen in labial (c) and lingual (d) views and close up (e) of partially obscured, in situ replacement tooth crown (arrow) in lingual view; f, $g$ - dorsal part of left squamosal, OMNH 67107, in lateral (f) and medial (g) views; $h$, i - anterior part of left frontoparietal, OMNH 67109, in dorsal (h) and ventral (i) views; $\mathbf{j}, \mathbf{k}$ - median part of left frontoparietal, OMNH 67110, in dorsal (j) and ventral (k) views. 1 , $\mathrm{m}$ - cf. Scotiophryne sp., incomplete left maxilla, AMNH FARB 33045, in labial (l) and lingual (m) views, from Judith River Formation, Clambank Hollow, Montana.

$16 \mathrm{Aj}-1, \mathrm{Bd})$ from the Kaiparowits Formation. Both squamosals (only one example is depicted in Text-fig. 3f, g) are from the left side and preserve the dorsal portion (processus posterodorsalis) of the lamella alaris. Two fragmentary, left frontoparietal specimens are available: OMNH 67109 consists of the anterior end, whereas OMNH 67110 preserves the bone adjacent to the posterior portion of the margo orbitalis and the processus lateralis (Text-fig. $3 \mathrm{~h}, \mathrm{i}$ and j, k, respectively).

Collectively, the figured specimens most closely resemble homologous, referred cranial bones of Scotiophryne pustulosa from the Bug Creek Anthills locality (mixed late Maastrichtian and early Paleocene; Hell Creek Formation), Montana, and from the Lance Formation (late Maastrichtian), Wyoming, in the following features (cf. Estes 1969: fig. 2; Gardner 2008: fig. 13.1L-T): moderate size; external surfaces ornamented with a shagreen of small, bead-like tubercles; on the maxilla teeth are present, the processus zygomatico-maxillaris is moderately tall (i.e., extends a noticeable distance above the level of the margo orbitalis) and is grooved dorsally for contact with the squamosal, the lamina horizontalis is moderately deep and lingually wide, and has a convex lingual surface, and judging by their broken bases, the processus pterygoideus was at least moderately prominent; the dorsal portion of the squamosal is bluntly rounded and its smooth edges indicate it did not contact other skull bones; and the frontoparietals were paired and not in broad contact anteriorly with the nasals, although they likely at least partially overlapped the sphenethmoid.

Remarks: The monotypic species Scotiophryne pustulosa has the distinction of being the first Cretaceous anuran species to be named from North America (Estes 1969). The holotype is an ilium, but more distinctive are the referred skull bones (maxilla, squamosal, nasal, and frontoparietal) bearing the characteristic bead-like or pustulate ornament that inspired the specific epithet. The skull bones figured here from the Kaiparowits Formation are assigned to $S$. pustulosa because they closely resemble geologically younger (late Maastrichtian and ?early Paleocene) examples of the same bones previously referred to the species (Estes 1969: fig. 2; Gardner 2008: fig. $13.1 \mathrm{~L}-\mathrm{T})$ and because they conform to the most recent, revised diagnoses for S. pustulosa (Gardner 2008, Roček 2013). The newly reported maxillae and squamosals provide no new information about these elements in S. pustulosa, because these specimens are less complete than examples previously reported from the Bug Creek Anthills and the Lance Formation. The new frontoparietal specimens confirm that these bones were paired and one (OMNH 67110: Text-fig. 3j, k) provides new information about the more posterior portion of this bone, as follows: the margo orbitalis is broadly concave medially and laterally overhangs the braincase wall; the processus lateralis projects only a short 
distance laterally and is blunt in dorsal or ventral outline; medial to the margo orbitalis and processus lateralis, the ventral surface bears a ventrally projecting flange (pars contacta) that extends anteroposteriorly (the anterior continuation of this flange can be seen on the other frontoparietal, OMNH 67109: Text-fig. 3i); and more medially the ventral surface bears a shallow, ventrallyprojecting, bony patch that represents part of an incrassatio frontoparietalis. Unfortunately, OMNH 67110 is too fragmentary to establish further details about the incrassation, such as its outline and extent.

Originally described from the late Maastrichtian and early Paleocene of Montana and Wyoming (Estes 1969), Scotiophryne since has been reported from at least nine formations of Campanian - Paleocene age in the Western Interior of Canada and the USA (see summaries by Gardner 2008, Roček 2013, Gardner and DeMar 2013). Ours is not the first report of $S$. pustulosa from the Kaiparowits Formation. Eaton et al. (1999: table 11) included the species in a faunal list for the formation and subsequently Roček et al. (2010: 379, fig. 16Aj-1 and Bd) described incomplete S. pustulosa maxillae from UMNH locality VP 108 in the lower part of the formation. Skull bones reported here come from localities in both the lower (OMNH V9) and upper (OMNH V5 and V61) parts of the Kaiparowits Formation, and demonstrate that $S$. pustulosa was broadly distributed stratigraphically through the formation. Other Judithian reports for Scotiophryne in the Western Interior (see Appendix 2) are in the Mesaverde Formation in Wyoming (Breithaupt 1985, DeMar and Breithaupt 2006, 2008), the upper (Judithian) portion of the Wahweap Formation in Utah (Roček et al. 2010), and the Fruitland Formation in New Mexico (Armstrong-Ziegler 1978, 1980, Hunt and Lucas 1992, 1993). Roček et al. (2010) also reported slightly older occurrences for the species (all founded on ilia) at three localities in south-central Utah: one locality in the lower (early Campanian) part of the Wahweap Formation (Roček et al. 2010: fig. 13a, b, d); a second locality of similar age that may also lie in the Wahweap Formation (Roček et al. 2010: fig. 14t); and a late Santonian age locality in the John Henry Member of the Straight Cliffs Formation (Roček et al. 2010: fig. 10B). The last is likely the oldest occurrence for the species. Recently, Oreska et al. (2013) reported cf. Scotiophryne sp. on the basis of fragmentary skull bones (a maxilla and some indeterminate bones) from the middle part of the Cloverly Formation (Aptian - Albian) of Wyoming. Although their figured maxilla does bear pustulate ornament (Oreska et al 2013: fig. 8A, B), considering that pattern of ornament is not unique among anurans to Scotiophryne and that the Cloverly specimens are at least 15 million years older than the oldest Utah examples, we (as did Oreska et al. 2013) suspect the Cloverly specimens do not pertain to Scotiophryne. Outside of the Western Interior, there are reports of Scotiophryne in two Campanian formations: the El Gallo Formation (possibly "Edmontonian" equivalent; see Cifelli et al. 2004, Kielan-Jaworowska et al. 2004) in Baja California, Mexico (Estes and Sanchiz 1982) and the Marshalltown Formation (possibly Judithian or Aquilan equivalent; see Cifelli et al. 2004, Kielan-Jaworowska et al. 2004) in New Jersey, USA (Denton and O'Neill 1998); neither occurrence can be verified, because the relevant specimens (skull and postcranial bones from Baja California; maxilla from New Jersey) have not been described or figured.

\section{cf. Scotiophryne sp.}

(Text-fig. 31, m)

Material and occurrences: Maxilla from Judith River Formation, Montana, USA (Appendix 2).

Description: The sole example, AMNH FARB 33045 , is an incomplete left maxilla about $6.3 \mathrm{~mm}$ in preserved length (Text-fig. 31, m). It preserves the suborbital region and the adjacent pre- and postorbital regions. Anteriorly the specimen is broken through the base of the processus frontalis and posteriorly it is broken just behind the level of the processus pterygoideus. The preserved portion of the pars facialis is moderately deep. Its incomplete pre-and postorbital portions are moderately high, and enclose between them a moderately concave margo orbitalis that is lingually thickened. A well-developed facet for contact with the squamosal extends anteriorly along the dorsolingual surface of the preserved portion of the processus zygomatico-maxillaris, onto the adjacent (i.e., posterior) portion of the suborbital region. Although it is sheared off, judging by its broken base the processus pterygoideus would have been well developed. The lamina horizontalis is relatively deep and lingually narrow, with its lingual surface vertical and shallowly convex lingually. The posteriorly incomplete tooth row extends posteriorward at least as far as the level of the processus pterygoideus. No teeth are intact, but smooth rims on the better preserved bases suggest the teeth were pedicellate. The labial surface of the pars facialis is ornamented. Across the preserved portion of the postorbital region and about the posterior three-quarters of the suborbital region, labial ornament consists of small, moderately spaced tubercles. More anteriorly, those tubercles give way to low, irregular ridges enclosing shallow pits. The ventral portion of the ornamented surface is dominated by short, irregular ridges oriented horizontally along the posterior portion and shallowly inclined dorsally along the anterior portion.

R e m a rks: In terms of its general structure and size, the above-described maxilla from Clambank Hollow is most similar to Judithian and Lancian maxillae of Scotiophryne pustulosa (Estes 1969: fig. 2c-f; Gardner 2008: fig. 13.1L-M; Roček et al. 2010: fig. $16 \mathrm{Aj}-1$ and $\mathrm{Bd}$; here: Text-fig. 3a-d) and Judithian maxillae described below for our unnamed genus and species I (Text-fig. 6a-h). It differs from both in being slightly deeper through the suborbital region and in that its labial ornament is somewhat intermediate, being predominantly formed by tubercles but also with some ridges. Even in the region where the Scotiophryne-like ornament is best developed on AMNH FARB 33045, those bony tubercles are more broadly separated, rather than being more closely packed as in examples from the Judithian of Utah (Roček et al. 2010: fig. 16Aj-1; here: Text-fig. 3a, b) and especially in geologically younger maxillae from the Lance and Hell Creek formations (Estes 1969: fig. 2d, e; Gardner 2008: fig. 13.1L, N). To highlight the distinctiveness of this unusual maxilla from the Judith River Formation and in recognition of its Scotiophryne-like ornament, we identify this specimen as cf. Scotiophryne sp. 


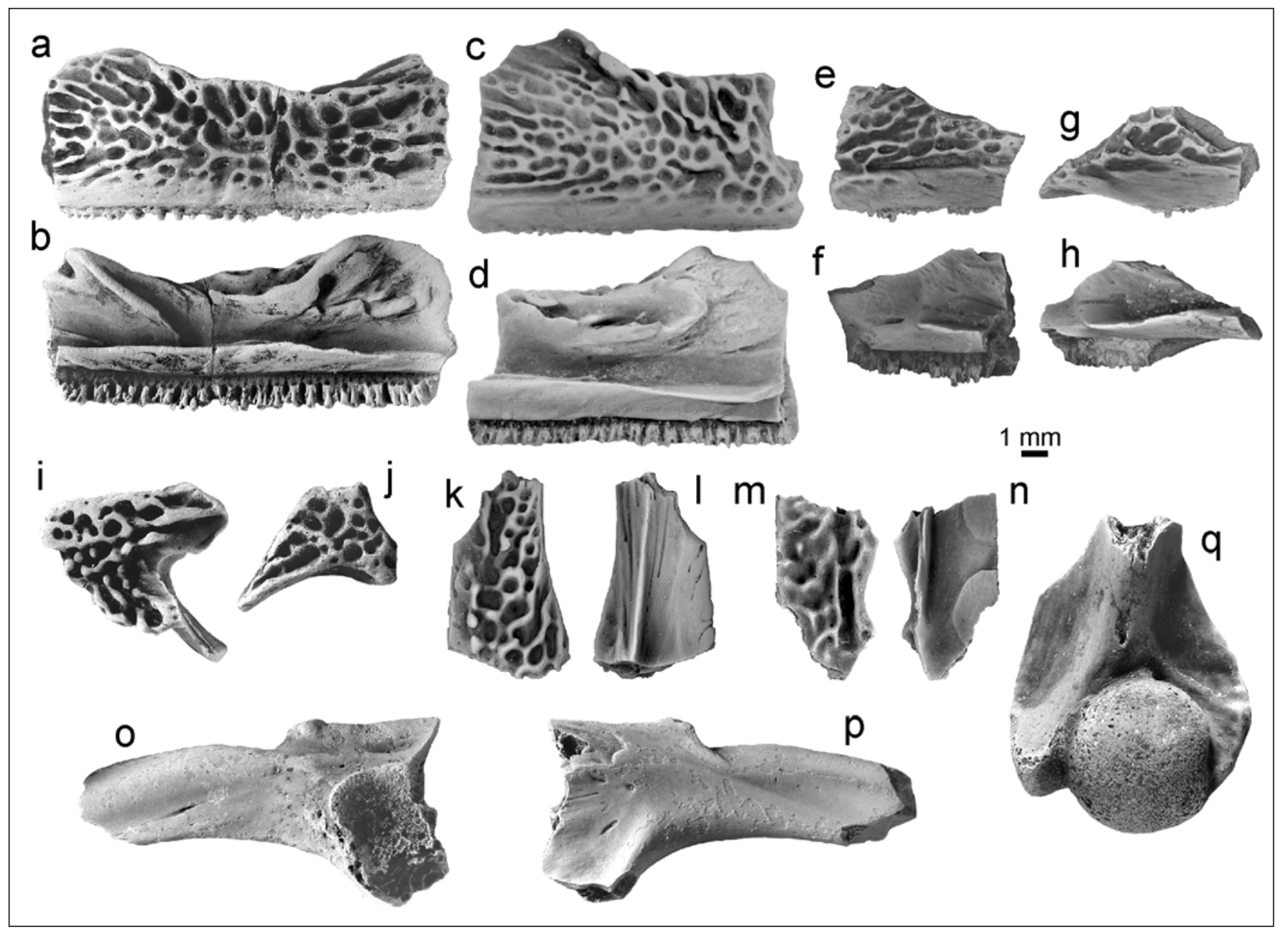

Text-fig. 4. Skull and postcranial bones of Hensonbatrachus kermiti GARDNER et BRINKMAN, 2015 from the middle - late Campanian (Judithian) of Alberta, Canada and Montana, USA. All images are photographs and depict specimens lightly dusted with ammonium chloride to enhance details and texture. Images at same magnifications; see scale bar. a, b - nearly complete right maxilla (holotype), UALVP 40167, in labial (a) and lingual (b) views, from Dinosaur Park Formation, Irvine locality, Alberta. c, d - incomplete right maxilla, UALVP 40202, in labial (c) and lingual (d) views, from Dinosaur Park Formation, Irvine locality, Alberta. e, f - incomplete left maxilla, AMNH FARB 33042, in labial (e) and lingual (f) views, from Judith River Formation, Clambank Hollow locality, Montana. g, h - incomplete left maxilla, AMNH FARB 33043, in labial (g) and lingual (h) views, from Judith River Formation, Clambank Hollow locality, Montana. i - nearly complete left squamosal, UALVP 40171, in lateral view, from Dinosaur Park Formation, Irvine locality, Alberta. j - nearly complete left nasal, UALVP 40170, in dorsal view, from Dinosaur Park Formation, Irvine locality, Alberta. $k$, l anterior part of right frontoparietal, UALVP 40173, in dorsal (k) and ventral (l) views, from Dinosaur Park Formation, Irvine locality, Alberta. m, n - median part of right frontoparietal, TMP 1986.023.0032, in dorsal (m) and ventral (n) views. o, p - left ilium, TMP 1974.010.0088, in lateral (o) and medial (p) views, from Dinosaur Park Formation, TMP locality L0086, Dinosaur Provincial Park, Alberta. q - distal end of left humerus, UALVP 40176, in ventral view, from Dinosaur Park Formation, Irvine locality, Alberta.

\section{Hensonbatrachus kermiti GARDNER et BRINKMAN, 2015}

(Text-fig. 4)

Material and occurrences: Maxillae (including holotype), squamosals, nasal, frontoparietals, humerus, and ilia from Dinosaur Park and Oldman formations, Alberta, Canada; maxillae from Judith River Formation, Montana, USA (Appendix 2).

D e s c r i p t i o n: The detailed description of skull bones (maxillae, squamosals, nasal, and frontoparietals), ilia, and humerus provided by Gardner and Brinkman (2015) in the recent type description for Hensonbatrachus kermiti does not need to be repeated. Instead, here we simply figure examples of those elements (Text-fig. $4 \mathrm{a}-\mathrm{d}, \mathrm{i}-\mathrm{j}$ ). During the course of our review, two previously unreported maxillae (Text-fig. $4 \mathrm{e}-\mathrm{h}$ ) were identified from the Judith River Formation, Montana. Both specimens are moderately large and robust, are from the left side, and are broken dorsally, anteriorly, and posteriorly. Each preserves the region bearing the processus pterygoideus, specifically the more posterior part of the suborbital region, the adjacent part of the postorbital region, and a posterior portion of the tooth row. The more nearly complete specimen, AMNH FARB 33042 (Text-fig. 4e, f) preserves enough of the processus zygomatico-maxillaris and suborbital region to demonstrate that those portions of the maxilla were at least moderately high. In lingual view, both specimens bear a small, weakly-developed, scoop-shaped processus pterygoideus arising at the posterior end of 
a ledge-like lamina horizontalis; the latter is moderately deep and lingually wide, and has a flattened lingual face that faces slightly ventrally. In both specimens, the labial surface of the bone above the level of the crista dentalis is ornamented with moderately deep and irregularlyshaped pits and short grooves that are bordered by moderately tall, thick, and vermiform ridges.

R e m a rks : As described by Gardner and Brinkman (2015) Hensonbatrachus kermiti is a distinctive anuran characterized by a unique combination of features, including its pattern of cranial ornament, form and contacts of its maxilla and squamosal, pattern of its frontoparietal incrassations, and iliac features. Compared to other known Late Cretaceous frogs from North America, Hensonbatrachus was relatively large, with an estimated snout - vent length of 75-115 mm. Based on its body size, robustly built bones, and ornamented skull bones, Hensonbatrachus was interpreted as a generalized, ground dwelling anuran.

All specimens included in the type description for Hensonbatrachus kermiti came from localities in the lower and middle parts of the Dinosaur Park Formation and the upper part of the underlying Oldman Formation, both in southeastern Alberta (Gardner and Brinkman 2015; here: Appendix 2). The first examples were collected in the mid-1960s. The somewhat Eopelobates-like ornament on the maxilla, squamosal, and skull roof bones may have been the basis for "Eopelobates n. sp." and "Eopelobates" having been recorded in preliminary faunal lists for the region (e.g., Fox 1976a and Currie 1986, respectively). One of us (Gardner 2000) informally recognized and briefly described the species now known as H. kermiti in his $\mathrm{PhD}$ dissertation as "Genus and Species Unnamed B".

The two maxillae described here are from the paracontemporaneous Judith River Formation, farther to the south at Clambank Hollow in central Montana. These newly recognized specimens are the first record for the species outside of Alberta. Although both specimens are fragmentary, they can be reliably assigned to $H$. kermiti on the basis of their moderately large size and robust build, presence of teeth, structure of the lamina horizontalis and the processus pterygoideus, and pattern of labial ornament. Although we did not find examples of other skull or postcranial bones of $H$. kermiti among the small collection of anuran fossils made by Ashok Sahni from Clambank Hollow in the mid-1960s, we predict such specimens might remain to be identified in more recent collections from other localities in the type area of the Judith River Formation (e.g., see Blob et al. 2001, Rogers and Brady 2010).

\section{Tyrrellbatrachus brinkmani GARDNER, 2015}

(Text-fig. 5a-f)

Material and occurrences: Seven incomplete maxillae (holotype and six referred) from Dinosaur Park Formation, Alberta, Canada (Appendix 2).

R e marks: Tyrrellbatrachus brinkmani was established for seven incomplete maxillae, each preserving varying amounts of the posterior portion of the suborbital region and adjacent portion of the postorbital region. Although the complete structure of the maxilla is unknown, the available specimens are distinctive among known North American Cretaceous anuran maxillae and species in exhibiting a unique combination of features (see three examples in Text-fig. 5a-f), including the moderate size and robustness of the bone, lack of teeth (i.e., edentulous), the margo orbitalis is shallowly concave, the crista dentalis is relatively shallow and its lingual surface is perforated by tiny foramina, the processus pterygoideus is prominently developed and triangular, the processus zygomatico-maxillaris is moderately tall and has a thin, smooth dorsal edge (suggesting no sutural contact with the squamosal), and the labial surface of the maxilla, especially in the suborbital region and in larger specimens, has a roughened texture. The described size series indicates that with growth maxillae lose much of the pitted labial texture seen in smaller maxillae and develop a groove that descends anteroventrally along the labial surface at the junction between the processus zygomatico-maxillaris and suborbital region.

The first examples of Tyrrellbatrachus brinkmani maxillae were collected in the mid-1980s by Donald Brinkman (one of the founding research scientists at the Royal Tyrrell Museum of Palaeontology) from vertebrate microfossil localities in the basal portion of the Dinosaur Park Formation, in the Dinosaur Provincial Park area. All seven reported maxillae are from that same restricted stratigraphic interval and region (Gardner 2015). No examples of maxillary specimens preserving the more anterior portion of the bone or other skull bones that potentially could be associated (e.g., on the basis of similar roughened external texture, complementary features, and provenance) with the described maxillary specimens of T. brinkmani have yet been recognized from localities in the Dinosaur Park Formation.

Tyrrellbatrachus brinkmani maxillae are superficially similar to those of Theatonius (see Text-fig. $5 \mathrm{~g}, \mathrm{~h}$ and next account) in being edentulous, but the former differ in being relatively larger, in lacking the distinctive pustulate labial ornament of Theatonius, and in numerous details of the lingual surface and inferred pattern of squamosal contact.

\section{Theatonius Fox, 1976b}

R e m a r k s : Known by isolated skull bones, Theatonius is distinctive among known Mesozoic anurans, yet its relationships are uncertain (Fox 1976b, Estes and Sanchiz 1982, Duellman and Trueb 1986, Roček 2000, 2013, Holman 2003, Gardner 2008, Blackburn and Wake 2011). Theatonius lancensis, the type and only described species in the genus, is best known from a small collection of isolated maxillae (including the holotype), squamosals, and frontoparietals from one locality (Bushy Tailed Blowout, Wyoming, USA) in the upper Maastrichtian (Lancian NALMA) Lance Formation (Fox 1976b, Gardner 2008). An isolated maxilla currently referred to $T$. lancensis has been reported (Gardner and DeMar 2013, Mercier et al. 2014), but not yet described, from the paracontemporaneous Hell Creek Formation in Montana, USA. 


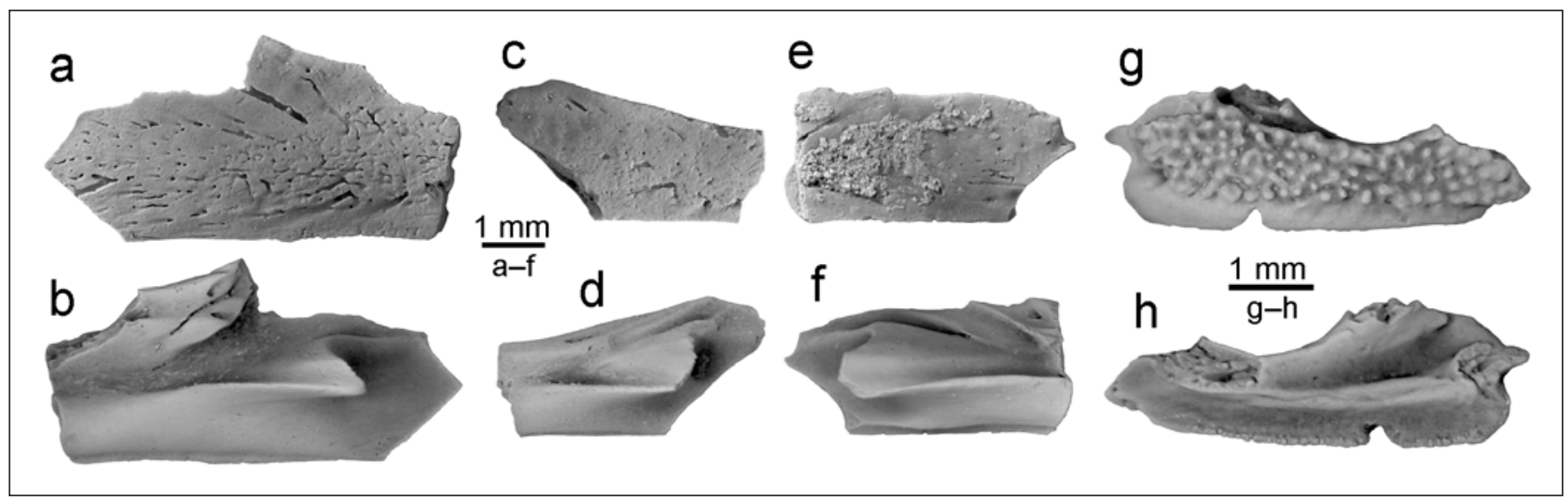

Text-fig. 5. Edentulous anuran maxillae from the middle - late Campanian (Judithian) of Alberta, Canada and Utah, USA. All images are photographs and depict specimens lightly dusted with ammonium chloride to enhance details and texture. Images at different magnifications; see corresponding scale bars. a-f - Tyrrellbatrachus brinkmani GARDNER, 2015, all from basal part of Dinosaur Park Formation, Dinosaur Provincial Park, Alberta: a, b - incomplete right maxilla, TMP 1985.066.0035 (holotype), in labial (a) and lingual (b) views, from TMP locality L0404; c, d - incomplete right maxilla, TMP 1986.033.0033, in labial (c) and lingual (d) views, from TMP locality L0031; e, f - incomplete left maxilla, TMP 1986.214.0032, in labial (e) and lingual (f) views, from TMP locality L0051. g, h Theatonius n. sp., nearly complete left maxilla, OMNH 67082, in labial (g) and lingual (h) views, from Kaiparowits Formation, OMNH locality V6, Utah.

\section{Theatonius n. sp.}

\section{(Text-fig. 5g, h)}

Material and occurrences: Six maxillae from Kaiparowits Formation, Utah, USA (Appendix 2).

Description: The six maxillary specimens include a fragmentary example from the UMNH collections previously figured as being from an unidentified anuran (Roček et al. 2010: fig. 16Ab) plus five more recently identified examples from the OMNH collections: a nearly complete left maxilla (OMNH 67082; Text-fig. 5g, h) and four less complete maxillae (unfigured). Collectively these six specimens document the entire structure of the maxilla. These specimens are strikingly similar to maxillae of the late Maastrichtian (Lancian) anuran Theatonius lancensis (see revised species diagnosis by Gardner 2008) in the following features: small size (OMNH 67082 is $4.9 \mathrm{~mm}$ long); labial surface ornamented with moderate-sized and closely packed pustules; crista dentalis moderately deep and lacks teeth; lamina horizontalis a weakly developed and lingually convex ridge; margo orbitalis deeply and asymmetrically concave; preorbital area taller and longer than postorbital area; processus palatinus relatively massive, projects linguodorsally, and dorsally bears a prominent facet; groove for ductus nasolacrimalis deep, wraps around labial base of processus palatinus and extends onto margo orbitalis; anterior portion of lamina anterior lingually bears a prominent facet; rostellum small, pointed, and directed anteriorly; processus pterygoideus lingually short, but anteroposteriorly elongate, and bears prominent articular facet that wraps posterodorsally onto processus zygomatico-maxillaris; and posterior end of processus posterior bluntly pointed.

R e m a r k s : As indicated above, maxillae reported here from the Kaiparowits Formation compare favourably with the type species Theatonius lancensis. The one notable difference is that the occlusolingual rim of the pars dentalis bears a row of tiny bumps in the Utah specimens, whereas that margin is smooth in the two maxillae (holotype and one referred: Gardner 2008: fig. 13.2A-D and E, respectively) described for Theatonius lancensis from the Lance Formation. That morphological difference, coupled with differences in ages (i.e., middle - late Campanian vs. late Maastrichtian), suggest the maxillae from the Kaiparowits Formation pertain to a second species of Theatonius. Unfortunately, no examples of the equally distinctive frontoparietals or squamosals comparable to those known for T. lancensis (see Fox 1976b, Gardner 2008: fig. 13.2F-J) have been identified among the Utah samples.

The occurrence of Theatonius in the Kaiparowits Formation of south-central Utah extends the geographical range for the genus southwards into Utah from Wyoming (Fox 1976b) and Montana (Gardner and DeMar 2013, Mercier et al. 2014) and extends its temporal range back from the late Maastrichtian to the middle - late Campanian. There also is an unconfirmed report of Theatonius-like squamosals in the Campanian (possibly Aquilan or Judithian equivalent; see Cifelli et al. 2004, Kielan-Jaworowska et al. 2004) Marshalltown Formation of New Jersey (Denton and O’Neill 1998). Compared to the apparently restricted distribution of T. lancensis in the Lance Formation, where it is known only from the Bushy Tailed Blowout locality, the putative new species of Theatonius from Utah has a broader stratigraphic distribution, being represented at five localities in both the lower (OMNH V6 and V9; UMNH VP 108) and upper (OMNH V5 and 61) parts of the Kaiparowits Formation.

\section{Unnamed Genus and Species I}

\section{(Text-fig. 6)}

Material and occurrences: Maxillae, squamosals, nasals, frontoparietals, and possibly ilia from Dinosaur Park Formation, Alberta, Canada; maxilla and 


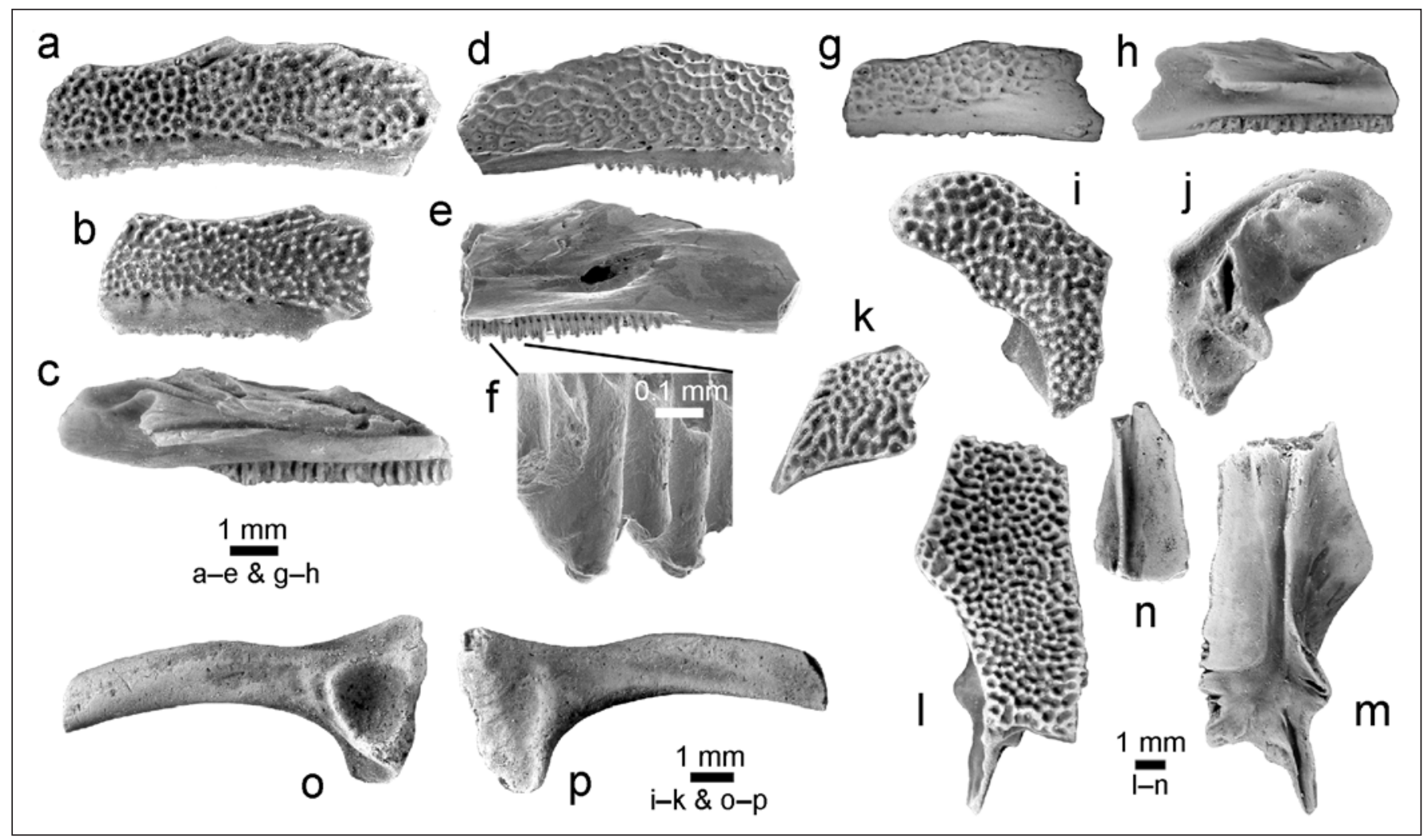

Text-fig. 6. Skull bones and tentatively associated ilium of Anura unnamed genus and species I from the middle - late Campanian (Judithian) of Alberta, Canada and Montana, USA. Except where noted otherwise, images are photographs and depict specimens lightly dusted with ammonium chloride to enhance details and texture. Images at different magnifications; see corresponding scale bars. a - incomplete left maxilla, UALVP 40177, in labial view, from either Dinosaur Park Formation or Oldman Formation, UALVP locality DM-19, Alberta. b - incomplete left maxilla, UALVP 40179, in labial view, from Dinosaur Park Formation, Railway Grade locality, west of Dinosaur Provincial Park, Alberta. c - incomplete left maxilla, UALVP 40178, in lingual view, from either Dinosaur Park Formation or Oldman Formation, UALVP locality DM-19, Alberta. d-f - incomplete right maxilla, TMP 2008.004.0016, entire specimen in labial (d) and lingual (e) views and close up (f) of two intact teeth in anterolingual view (all three images are scanning electron micrographs), from Dinosaur Park Formation, TMP locality L0086, Dinosaur Provincial Park, Alberta. g, h - incomplete left maxilla, AMNH FARB 8460, in labial (g) and lingual (h) views, from Judith River Formation, Clambank Hollow, Montana. i, j, dorsal part of right squamosal, UALVP 40181, in lateral (i) and medial (j) views, from Dinosaur Park Formation, Irvine locality, Alberta. $\mathrm{k}$ - incomplete left nasal, UALVP 40810, in dorsal view, from Dinosaur Park Formation, Irvine locality, Alberta. 1 , $m$ anteriorly incomplete left frontoparietal, UALVP 40182, in dorsal (l) and ventral (m) views, from Dinosaur Park Formation, Irvine locality, Alberta. $n$ - anterior end of right frontoparietal, UALVP 40183, in ventral view, from Dinosaur Park Formation, Irvine locality, Alberta. o, p - incomplete left ilium, UALVP 40184, in lateral (o) and medial (p) views, from Dinosaur Park Formation, Irvine locality, Alberta.

squamosal from either Dinosaur Park Formation or Oldman Formation, Alberta, Canada; and maxilla from Judith River Formation and skeleton from Two Medicine Formation, both Montana, USA (Appendix 2).

D e s c r i p t i o n : Pending further preparation and study of the skeleton from the Two Medicine Formation (see Gardner and DeMar 2013: fig. 2q), here we provide brief descriptions from other formations of isolated skull bones and, potentially, an ilium that also are assignable to this unnamed taxon.

None of the available maxillae (Text-fig. 6a-h) preserves the portion of the bone anterior to the margo orbitalis. Collectively, these specimens reveal the following features: the pars facialis is moderately tall; the margo orbitalis is shallowly concave and moderately elongate; the postorbital region is moderately elongate, with the processus posterior being bluntly rounded posteriorly and the processus zygomatico-maxillaris being low and grooved dorsally and dorsolingually for contact with squamosal; the lamina horizontalis is a moderately deep and lingually wide ridge, with a flattened or shallowly convex lingual face; the processus pterygoideus is a well-developed, medially projecting flange, with its dorsal surface shallowly concave and slightly roughened for contact with the pterygoid; and the posterior end of the tooth row lies slightly behind the level of the processus pterygoideus. Labial ornament on the pars facialis consists of low, narrow ridges arranged in a reticulate to anastomosing pattern and enclosing shallow, irregular-shaped pits. On some specimens (e.g., Text-fig. 6a, b) the ridges break up towards the central portion of the bone into short, isolated ridges and tiny tubercles. One specimen (TMP 2008.004.0016: Text-fig. 6e, f) preserves several intact teeth bearing labio-lingually bicuspid crowns with disc-shaped cuspules. 
The available squamosals (e.g., Text-fig. 6i, j) preserve the middle and dorsal part of the bone, which externally (laterally) bears ornament similar to that on the maxilla. The preserved portion of the lamella alaris is anteroposteriorly narrow and inclined posterodorsally. A shallow bend along the posterior margin towards the base of the figured specimen implies that the complete bone was bent midway along its length, in a manner reminiscent of more nearly complete squamosals of Scotiophryne pustulosa (cf. Gardner 2008: fig. 13.1Q, R). The dorsoposterior edge of the processus posterodorsalis is broadly rounded and smooth, indicating it was not in sutural contact with the frontoparietal roof, unlike in casque-headed frogs and possibly in Theatonius (Fox 1976b, Gardner 2008).

None of the nasals is complete. The figured specimen (Text-fig. 6k) is an anteriorly and medially incomplete left nasal that dorsally bears ornament similar to that on the maxilla. The processus paraorbitalis is triangular, confluent with the main body of the bone, and pointed. Judging by its preserved margins, the nasal may have been rhomboid in outline.

The two figured frontoparietal specimens collectively document most of the structure of this bone: UALVP 40182 (Text-fig. 61, m) is the posterior two-thirds of a left frontoparietal and UALVP 40183 (Text-fig. 6n) is the anterior one-quarter of a right frontoparietal. Both specimens dorsally bear ornament similar to that on the maxilla, nasal, and squamosal. The frontoparietals were paired in life, but broadly sutured medially with one another along at least the posterior two-thirds of their length. The more nearly complete specimen, UALVP 40182, reveals the following notable features: the posterior part of the bone is not expanded laterally (which is consistent with the above interpretation based on the squamosal that this taxon is not a casque-headed anuran); the processus posterior superior extends posteriorly from the posterolateral corner of the bone as an elongate prong; the margo orbitalis is broadly concave medially and laterally overhangs the braincase wall; the processus lateralis projects a moderate distance laterally and is bluntly triangular in dorsal or ventral outline; the ventral flange (pars contacta) on the underside of the bone is narrow and, except at its posterior end, extends antero-posteriorly in a straight line; and the incrassatio frontoparietalis is undivided (i.e., it spans across both the left and right frontoparietals), elongate, and narrows anteriorly. UALVP 40183 shows that the anterior end of the frontoparietal was somewhat pointed and was not broadly sutured anteriorly with the nasal; the extent to which the frontoparietal may have overlapped the sphenethmoid (not known for the species as an isolated bone) is unknown. The ventral surface of UALVP 40183 bears the anterior continuation of the pars contacta, but not of the incrassatio frontoparietalis.

The ilium depicted here (Text-fig. 6o, p) is from an individual comparable in size to those represented by many of the figured skull elements. This is a relatively simple bone: the shaft is slightly compressed laterally; there is no dorsal crest, tuber superior, spiral groove, or inter-iliac tubercle; the dorsal and ventral acetabular expansions (pars ascendens and pars descendens, respectively) are poorly developed and subequal in size; and the acetabular fossa is subcircular in outline and moderate in size, being fully enclosed within the limits of the acetabular region.

R e marks: We associate the above-listed, isolated skull bones on the strength of their ornament, size, complementary morphologies, and provenance and by comparisons with the articulated skull belonging to the undescribed skeleton from the Two Medicine Formation. In many respects, these skull bones resemble those referred to Scotiophryne pustulosa, but differ in having external ornament consisting of shallow pits enclosed by ridges that are low, narrow, arranged in a reticulate to anastomosing pattern, and in some places are broken into shorter, isolated ridges and tiny tubercles, versus the tightly packed, pustulate ornament characteristic for S. pustulosa. Size, ornament, presence of teeth, and structural details of the maxilla, squamosal, and frontoparietal serve to further differentiate this taxon from other Judithian anurans and specimens and establish it as a distinct taxon.

This taxon was first recognized in a $\mathrm{PhD}$ dissertation as "Genus and Species Unnamed A" (Gardner 2000: 544-547, fig. $12-4 \mathrm{~A}-\mathrm{K})$ on the basis of a small number of isolated maxillae, squamosals, nasals, frontoparietals, and ilia from screen washed vertebrate microfossil localities (especially Irvine) in the Dinosaur Park Formation and perhaps the Oldman Formation of southeastern Alberta. Further examination of collections from Irvine and other screen washed localities through the lower and middle portions of the Dinosaur Park Formation as well as Sahni's (1968, 1972b) small collection from Clambank Hollow in the upper portion of the Judith River Formation revealed further examples of isolated skull elements referable to this taxon. The sole maxilla (AMNH FARB 8460: Text-fig. 6g, h) reported here from the Judith River Formation was the exemplar for Sahni's (1972b: 347, fig. 7L-M) “discogossid C", which he characterized as "small frog with sculpted maxilla". Those surveys also revealed the presence in the Dinosaur Park and Judith River formations of additional anuran taxa and skull bones similar in size to, but differing in morphology from, our unnamed genus and species I. The co-occurrence of such similarly-sized anuran taxa compromises Gardner's (2000) original association of skull bones and ilia, which was based on provenance and size. For completeness, we have provided a brief description and figures for one of the originally referred ilia (Text-fig. 6o, p), but only tentatively associate it with the isolated skull bones. Images of that same ilium previously were published as "Anura new gen. and sp. A" (Gardner 2005: fig. 10.1) and "Anura indet." (Roček et al. 2012: fig. 3H). A recent and exciting development is that preparation of the most nearly complete of the fossil anuran skeletons (see Gardner and DeMar 2013: fig. 2q) mentioned by Varricchio (2002: 20) from the Two Medicine Formation, Montana, reveals that skeleton belongs to the same taxon as the above-listed, isolated skull bones. Because this skeleton promises to provide a wealth of information about the osteology and phylogenetic relationships of this taxon and is a more suitable choice for a future holotype, we do not formally name and diagnose this taxon here. 


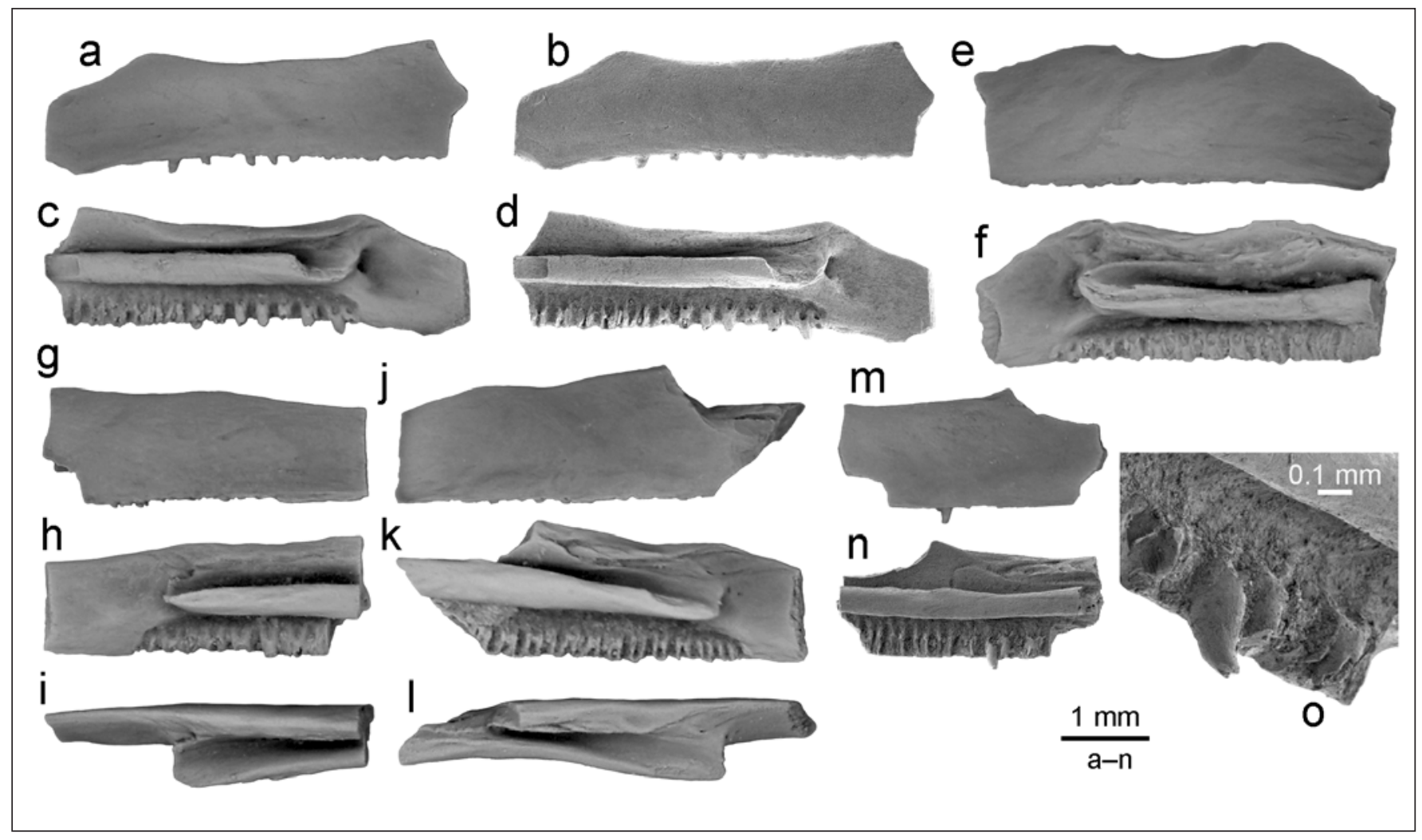

Text-fig. 7. Maxillae of Anura unnamed genus and species II from the middle - late Campanian (Judithian) of Utah, USA. All specimens are from OMNH locality V6 in the Kaiparowits Formation. Except where noted otherwise, images are photographs and depict specimens lightly dusted with ammonium chloride to enhance details and texture. Images at different magnifications; see corresponding scale bars. a-d - incomplete right maxilla, OMNH 67095, in labial (a, b) and lingual (c, d) views (images in b and d are scanning electron micrographs). e, f - incomplete left maxilla, OMNH 67098, in labial (e) and lingual (f) views. g-i - incomplete left maxilla, OMNH 67100, in labial (g) and lingual (h) views and, with anterior to right, in dorsal (i) view. $\mathrm{j}-\mathrm{l}$ - incomplete right maxilla, OMNH 67099, in labial (j) and lingual (k) views and, with anterior to left, in dorsal (l) view. $\mathrm{m}-\mathrm{o}$ - incomplete right maxilla, OMNH 67096, entire specimen in labial (m) and lingual (n) views and close up (o) of intact tooth in oblique lingual-anterior-ventral view (images in $n$ and $o$ are scanning electron micrographs).

\section{Unnamed Genus and Species II}

(Text-fig. 7)

Material and occurrences: Twelve maxillae from Kaiparowits Formation, Utah, USA (Appendix 2).

Description: Examples figured here from the OMNH collection (Text-fig. 7) and two previously figured examples from the UMNH collection (Roček et al. 2013: fig. $15 \mathrm{Ak}, 1)$ each preserves a portion of the suborbital region and most also preserve some portion of the adjacent postorbital region. The most nearly complete specimen (OMNH 67095: Text-fig. 7a-d) is broken anteriorly behind the processus palatinus and posteriorly through the processus posterior. This specimen is about $10 \mathrm{~mm}$ in preserved length and, based on comparisons with other anuran maxillae, likely was $15 \mathrm{~mm}$ or longer when intact. Other examples figured here are from slightly larger and smaller individuals. Compared to maxillae known for other anuran species from the Kaiparowits Formation, our unnamed genus and species II was intermediate in size between the smaller Theatonius n. sp. and the larger Scotiophryne pustulosa.

Although all of the available maxillary specimens are broken anteriorly and posteriorly, it is evident that the maxilla is elongate and low. The bone is labiolingually thickened and moderately robust through the suborbital region (which likely accounts for the preferential preservation of that portion), but markedly thinner through the postorbital region. In labial or lingual view the pars facialis is relatively low, the margo orbitalis is elongate and shallowly concave, and the processus zygomatico-maxillaris is a low, triangular projection. No specimen preserves the processus palatinus, but judging by the curvature along the anterior portion of the margo oribitalis in OMNH 67095 (Text-fig. 7a-d) the processus palatinus was taller than the processus zygomaticomaxillaris. The processus posterior is posteriorly elongate and becomes shallower posteriorly; both its dorsal and, to a lesser extent, its ventral margins decline posteroventrally at shallow angles. The dorsal edge of the processus zygomatico-maxillaris is thin and smooth, but in larger specimens a shallow sutural surface for contact with the squamosal extends along the dorsolingual portion of the process and onto the posterior portion of the margo orbitalis. The margo orbitalis is lingually thickened, especially in larger specimens. The lamina horizontalis is a well-developed and lingually projecting shelf that becomes wider posteriorly. In larger specimens, the lingual portion of the lamina horizontalis is thickened and curved upwards, which results 
in the dorsal surface of the shelf being gutter-like (e.g., Text-fig. 7c, d). The processus pterygoideus is moderately well developed. In larger specimens, the processus pterygoideus is triangular, projects lingually and slightly ventrally, and has a flat to shallowly concave dorsal surface. The posterior face of the processus posterior is variably perforated by a large pit (e.g., Text-fig. 7c). The labial surface of the maxilla is essentially smooth. The tooth row terminates posteriorly in line with or slightly past the level of the base of the processus posterior. Teeth are small, moderately spaced, and although it is not clear, appear to have been either non-pedicellate or weakly pedicellate. The sole intact tooth (Text-fig. 7o) has a labiolingually bicuspid crown bearing sub-pointed cuspules.

Remarks: The dozen maxillae reported here are distinctive among known North American Cretaceous anurans in their smooth labial surface, smaller size, overall form of the bone, details of lingual structures, and presence of teeth. The available size series shows that the wing-like processus pterygoideus, the dorsally curled lingual edge of the lamina horizontalis, and the sutural surface for contact with the squamosal along the dorsolingual face of the processus zygomatico-maxillaris and posterior portion of the margo orbitalis all become more pronounced with increased size, whereas other features (e.g., surface texture; relative position of posterior end of tooth row; low pars facialis; posteriorly elongate processus posterior) remain consistent.

The dozen maxillae are from two localities in the lower portion of the Kaiparowits Formation: OMNH V6 (ten OMNH specimens) and UMNH VP 51 (two UMNH specimens). No additional maxillae or other elements currently can be assigned to this taxon. Also from the lower portion of the Kaiparowits Formation, Roček et al. (2010) reported another four fragmentary maxillae that are smooth and dentate (UMNH VP 13324 and 18449: their figs 15Ah and 16Aa, respectively; UMNH VP 13263 and 18450: unfigured) and a fragmentary frontoparietal with a smooth dorsal surface (UMNH 13225; their fig. 15Aj). Some of those previously reported specimens might belong to the same taxon as the dozen maxillae listed here.

\section{Anura indeterminate morph 1}

\section{(Text-fig. 8)}

Material and occurrences: Maxilla from Dinosaur Park Formation, Alberta, Canada; maxillae from Judith River Formation, Montana, USA; maxillae from Mesaverde Formation, Wyoming, USA; maxillae and squamosal from Kaiparowits Formation; maxilla from Wahweap Formation; and maxillae from Aguja Formation, Texas, USA (Appendix 2).

Des cription: All figured examples (maxillae and a squamosal) are incomplete. Two maxillary specimens consist of the preorbital region. The more nearly complete specimen, (UALVP 40169: Text-fig. 8a, b), preserves an intact, relatively prominent processus palatinus and a nearly complete lamina anterior that is moderately tall, with its anterior end bluntly tapered and bearing only a rudimentary rostellum. The other specimen (AMNH FARB 8461:
Text-fig. 8c, d), is broken in front of the processus palatinus and is missing both the anterior and dorsal portions of the lamina anterior. The remaining maxillae (Text-fig. 8e-1) preserve portions along the suborbital region and, in some, also the region bearing the processus pterygoideus. Collectively the figured maxillary specimens show that this bone could be relatively large and robust, the pars facialis is moderately high, the margo orbitalis is shallowly concave in labial or lingual outline, the processus palatinus is well developed, the processus zygomatico-maxillaris is moderately tall and dorsolingually bears a facet for articulation with the squamosal, the lamina horizontalis is a well-developed bony shelf, the processus pterygoideus is robust, wing-shaped, and projects posterolingually for a short distance, and the posterior end of the tooth row (not intact in any specimen) extends back at least to the level of the processus pterygoideus. None of the maxillae has intact teeth, however, OMNH 23837 preserves several bicuspid replacement crowns in situ along the lingual surface of the crista dentalis (not figured). Although the lamina horizontalis is consistently deep along the suborbital region in all specimens, variation is evident in other aspects of its structure. In some specimens the lamina horizontalis may be relatively narrow (i.e., labio-lingual width less than vertical depth) and its lingual face shallowly convex and lingually directed (OMNH 23837; Text-fig. 8e). In others, the lamina horizontalis may be relatively wider (i.e., maximum labio-lingual width subequal to depth) and its lingual face either more deeply convex and directed lingually (OMNH 67094 and TMM 43057-256; Text-fig. 8h and j, respectively) or flatter and tilted ventrally (OMNH 25243; Text-fig. 81).

The figured squamosal (OMNH 23538: Text-fig. 8m, n) is an incomplete bone from the left side. It preserves the dorsal and posterior portions of the lamella alaris. Its medial surface preserves the broken base of the processus posterolateralis. The processus posterodorsalis is intact; that process is acuminate in medial or lateral outline, appears to have projected posterodorsally, and its smooth dorsal margin indicates it did not contact the frontoparietal. The smooth posterior face of the posterior margin of the squamosal and its overall shallowly concave profile suggest it formed the anterior rim of the tympanum.

A size range of individuals is represented by the maxillary and squamosal specimens. For the former, judging by the depth of the lamina horizontalis, the largest specimen (AMNH FARB 8461) is over twice as large as the smallest (OMNH 25243; cf. Text-fig. 8c, d versus 8k, 1). The squamosal probably is from a moderately large individual, perhaps comparable in size to the one represented by the maxilla OMNH 23837 (cf. Text-fig. 8m, n versus 8e, f) from the same formation. All maxillae and the squamosal are ornamented externally by narrow and moderately high ridges that are arranged in a reticulate pattern and enclose moderately broad, flat- or shallowly concave-bottomed pits. On the maxillae, this ornament is restricted to the pars facialis portion of the bone (i.e., about the upper two-thirds of the labial surface and, depending on the specimen, ridges may be in either an irregular polygonal pattern or more loosely arranged (cf. Text-fig. 8e, g, i, j versus $8 \mathrm{a}, \mathrm{c}$ ). As show by the maxilla UALVP 40169 (Text-fig. 8a), towards the anterior 


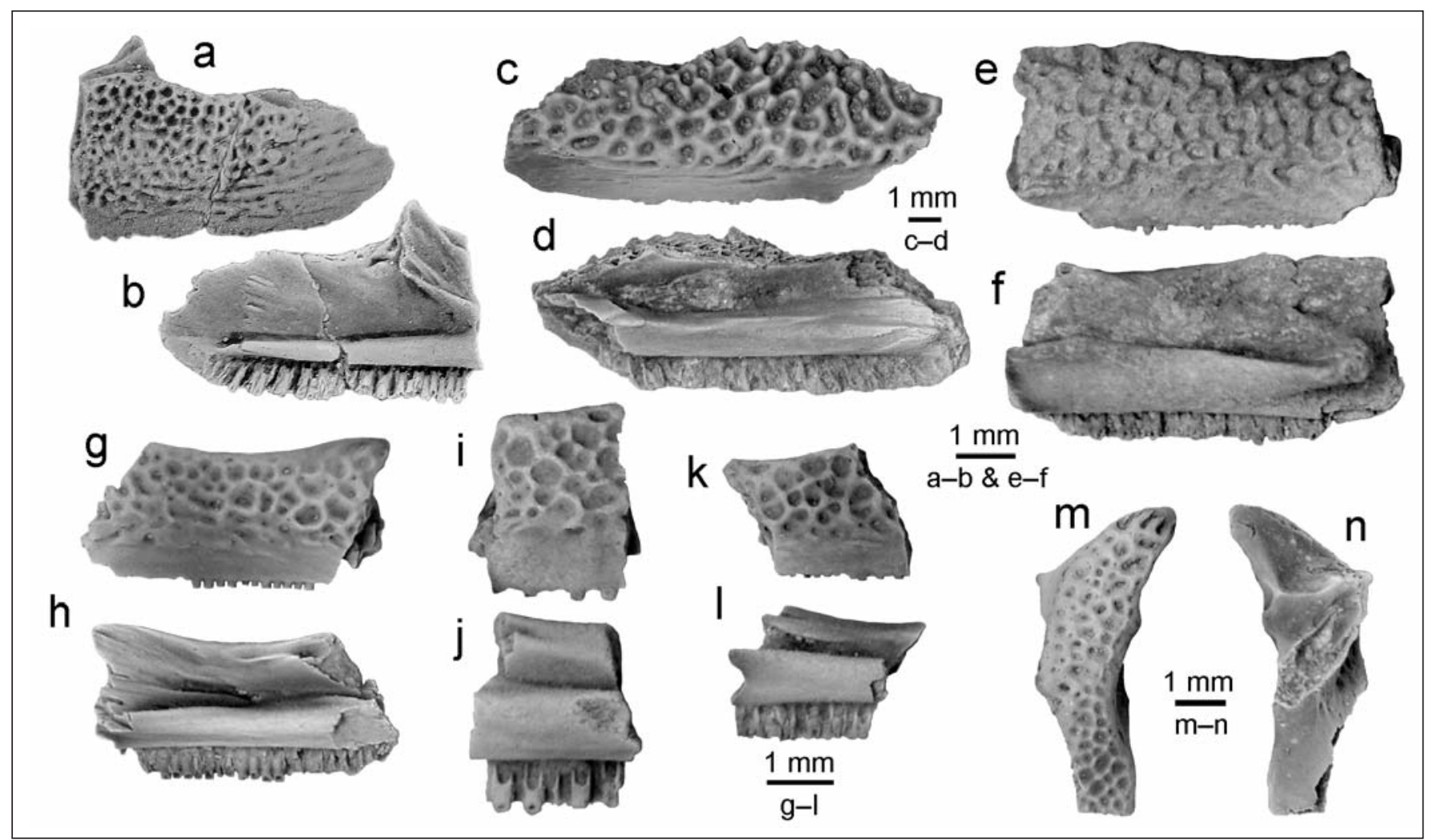

Text-fig. 8. Maxillae and squamosal of Anura indeterminate morph 1 from the middle - late Campanian (Judithian) of Alberta, Canada and Montana, Utah, and Texas, USA. All images are photographs and depict specimens lightly dusted with ammonium chloride to enhance details and texture. Images at different magnifications; see corresponding scale bars. a, b - incomplete right maxilla, UALVP 40169, in labial (a) and lingual (b) views, from Dinosaur Park Formation, Irvine locality, Alberta. c, d - incomplete left maxilla, AMNH FARB 8461, in labial (c) and lingual (d) views, from Judith River Formation, Clambank Hollow, Montana. e, f - incomplete right maxilla, OMNH 23837, in labial (e) and lingual (f) views, from Kaiparowits Formation, OMNH locality V5, Utah. g, h - incomplete left maxilla, OMNH 67094, in labial (g) and lingual (h) views, from Kaiparowits Formation, OMNH locality V6, Utah. i, j - fragmentary ?left maxilla, TMM 43057-256, in labial (i) and lingual (j) views, from Aguja Formation, OMNH locality V58/TMM locality 43057, Texas. k, I - fragmentary left maxilla, OMNH 25243, in labial (k) and lingual (l) views, from Aguja Formation, OMNH locality V58/TMM locality 43057, Texas. $\mathrm{m}, \mathrm{n}$ - incomplete left squamosal, OMNH 23538, in lateral (m) and medial (n) views, from Kaiparowits Formation, OMNH locality V6, Utah.

end of the bone the pit-and-ridge pattern is replaced by low, discontinuous ridges that roughly parallel one another and extend anteriorly and slightly dorsally.

R e m a rks: Specimens described above and listed in Appendix 2 for our morph 1 are grouped together largely on the basis of their style of pit-and-ridge labial ornamentation. That pattern clearly differs from the pustulate ornament characteristic for Scotiophryne and Theatonius (cf. Text-figs $3,5 \mathrm{~g}, \mathrm{~h}$ ) and the unornamented or weakly ornamented conditions seen in certain Judithian maxillae reported here (cf. Text-figs 5a-f, 7, 9, 10). Subtle, but consistent differences in details of their respective pit-and-ridge ornament also separate these morph 1 specimens from Hensonbatrachus, whose ornament is coarser and less regular in shape, consisting of deeper pits and short grooves enclosed by relatively thicker ridges (cf. Text-fig. $4 \mathrm{a}-\mathrm{n}$ ), and from our unnamed genus and species I, whose ornament is finer and more net-like, consisting of more irregular and smaller pits enclosed by narrower ridges that may break up into isolated ridges or tiny pillars (cf. Text-fig. 6a-m). Additional features related to size, form, and structures further differentiate morph 1 specimens from other Judithian maxillae and, where known, squamosals.

Historically, isolated fossil anuran skull bones having ornament similar to our morph 1 specimens have been compared to Eopelobates PARKER, 1929, an extinct pelobatid genus containing four species from the Eocene - Pliocene of Europe and two species from the Eocene of the USA; see recent revision by Roček et al. (2014) and references therein. Based largely on similarities to the cranial ornament in those Tertiary species (all of which are known by skeletons) isolated skull bones bearing reticulate ornament from the North American Late Cretaceous (Santonian - Maastrichtian) and early Paleocene routinely have been identified as belonging to Eopelobates or to an Eopelobates-like taxon (e.g., Estes et al. 1969, Estes 1970, Fox 1976a, Estes and Sanchiz 1982, Sanchiz 1998, Holman 2003, Gardner 2008, Gardner and DeMar 2013). As pointed out by Roček et al. (2014), such identifications were based entirely on general resemblances, especially the Eopelebates-like pattern of cranial ornament (which is relatively widespread among anurans as a whole), rather than synapomorphies or unique 


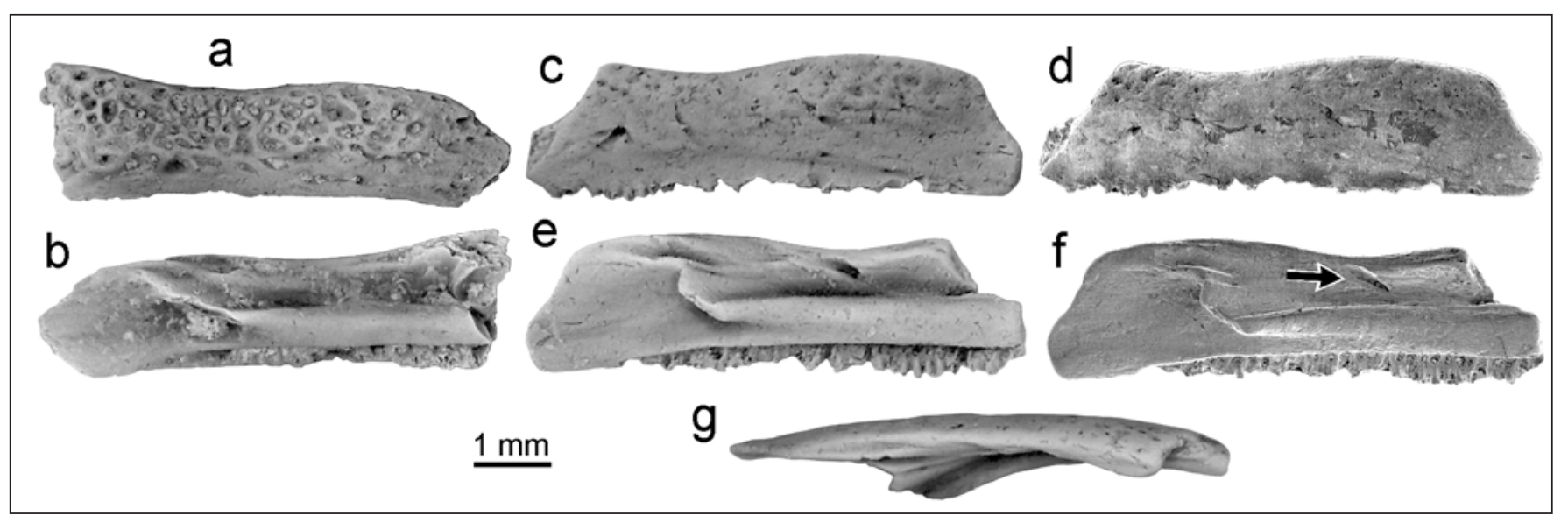

Text-fig. 9. Maxillae of Anura indeterminate morph 2 from the middle - late Campanian (Judithian) of Alberta, Canada. Both specimens are from the Irvine locality in the Dinosaur Park Formation. Except where noted otherwise, images are photographs and depict specimens lightly dusted with ammonium chloride to enhance details and texture. Images at same magnification; see scale bar. a, b incomplete left maxilla, UALVP 40191, in labial (a) and lingual (b) views. c-g - incomplete left maxilla, UALVP 40192, in labial (c, d) and lingual (e, $f$ ) views and, with anterior to right, in dorsal (g) view (images in $d$ and $f$ are scanning electron micrographs). Arrow (f) points at groove extending diagonally along lingual surface of pars facialis below margo orbitalis.

sets of features shared with the unequivocal Tertiary species of Eopelobates. Although using the name "Eopelobates" for such material has been a useful convention for labelling North American Late Cretaceous and Paleocene anuran fossils characterized by a reticulate, Eopelobates-like cranial ornament, following from Roček et al.'s (2014) critique of that practice and its potential for taxonomic confusion, here we instead use the informal name "morph 1" for these kinds of specimens.

Based on previous reports of Eopelobates-like occurrences and our examination of specimens available to us, we record Anura morph 1 in six of the ten formations included in our review (Appendix 2): Dinosaur Park Formation, Alberta; Judith River Formation, Montana; Mesaverde Formation, Wyoming; Kaiparowits and Wahweap formations, Utah; and Aguja Formation, Texas. Eopelobates-like anurans previously have been listed (no vouchers indicated) for the first four of those formations (e.g., Fox 1976a: 8 as "Eopelobates n. sp.", in what is now considered the Dinosaur Park Formation; Bryant 1989: 34 as "Eopelobates", in the Judith River Formation; Breithaupt 1985: 165 as "cf. Eopelobates sp.", in the Mesaverde Formation; Eaton et al. 1999: table 5 as "Eopelobates sp.", in the Kaiparowits Formation). "?Eopelobates sp." has long been recorded for the Fruitland Formation of New Mexico (Armstrong-Ziegler 1978, 1980, Hunt and Lucas 1992, 1993), on the basis of a fragmentary maxilla described and figured by Armstrong-Ziegler (1980: pl. 1c-d). However, judging by those published drawings, that specimen differs from North American Cretaceous maxillae historically assigned to "Eopelobates" and here to our morph 1 in having labial ornament formed by narrow, short, and irregular grooves instead of polygonal pits. Based on that difference, we regard the maxilla from the Fruitland Formation as indeterminate (see Appendix 2: "Other occurrences of Judithian anurans"). One of our morph 1 specimens (maxilla AMNH FARB 8461) from the Judith River Formation previously was designated by Sahni (1972b: 347 and fig. 7P-Q) as the exemplar for his "Discoglossid A", which he characterized as "large frog with sculpted maxilla". In our opinion, assignment of such a fragmentary maxilla to the Discoglossidae GÜNTHER, 1858, whether in the loose or strict sense of that name (cf. Sanchiz 1998 versus Frost et al. 2006) or to any other anuran family cannot be supported. Differences in size and lingual structure among the specimens assigned to our morph 1, plus the extensive latitudinal spread among their localities, suggest that our morph 1 grouping contains several species. Better preserved specimens will be needed to tease those species apart.

\section{Anura indeterminate morph 2}

(Text-fig. 9)

Material and occurrences: Two maxillae from Dinosaur Park Formation, Alberta, Canada (Appendix 2).

Description: The two specimens are both from the Irvine locality and preserve about the posterior two-thirds of a left maxilla. UALVP 40191 (Text-fig. 9a, b) lacks the posteriormost end of the processus posterior and most of the processus pterygoideus, but anteriorly preserves the base of the processus palatinus. UALVP 40192 (Text-fig. $9 \mathrm{c}-\mathrm{g}$ ) is broken farther behind the processus palatinus, but preserves an intact processus posterior and more of the processus pterygoideus. The two specimens are similar in size (UALVP 40191 is $6.0 \mathrm{~mm}$ long and UALVP 40192 is $6.7 \mathrm{~mm}$ long); the latter is from a slightly larger individual. They also resemble one another in the following features: bone elongate and low in labial or lingual outline; margo orbitalis shallowly concave and moderately elongate; processus zygomaticomaxillaris low and broadly convex dorsally, bearing grooves dorsolingually for contact with squamosal (these features are more prominently developed in the larger UALVP 40192); processus posterior only moderately elongate, with its posterodorsal edge moderately (UALVP 40191) or more 
steeply (UALVP 40192) declined; and lamina horizontalis moderately deep and lingually wide, with convex lingual surface. Although neither specimen retains any intact teeth, as indicated by their preserved tooth shafts the teeth are small and closely spaced. Judging by the profile along the anteriormost portion of the preserved dorsal edge in UALVP 40191, the processus frontalis would have been taller than the processus zygomatico-maxillaris. UALVP 40192 is informative for showing that the processus posterior tapers to a blunt point, that near its posterior end that same process lingually bears a small, shallow facet for contact with the jugal, and that the processus pterygoideus was a welldeveloped, lingually projecting flange with a shallowly concave dorsal surface. The specimens exhibit three differences. First, the posterior end of the tooth row lies approximately in line with (UALVP 40191) or slightly behind (UALVP 40192) the level of the processus pterygoideus. Second, a deep groove descends from the margo orbitalis anteroventrally along the lingual face of the pars facialis in UALVP 40192 (Text-fig. 9f: arrow), whereas no such groove is present in UALVP 40191. Finally, the labial surface of the pars facialis in UALVP 40191 is ornamented with low ridges that are arranged in a loosely reticulate pattern and enclose shallow pits, whereas in UALVP 40192 the labial surface is less obviously ornamented. Instead, the labial surface of the latter specimen has a roughened texture and, when viewed under low angle lighting, extremely low ridges enclosing shallow pits can be seen along the dorsal half of its labial surface. This less pronounced labial ornament does not seem to be an artefact of wear or abrasion.

R e m a r k s: The two small, low, and elongate maxillae from Irvine are similar to one another in many respects, but exhibit some differences (i.e., relative positions of posterior end of tooth row; variable presence of groove lingually below margo orbitalis; expression of labial ornament). The presence of more prominently expressed labial ornament in the smaller specimen is at odds with the general trend of cranial ornament (where present) becoming more pronounced with growth in anuran species. Determining whether these maxillae belong to separate species or simply are variants within a single species will require additional specimens. Even with this uncertainty, UALVP 40191 and 40192 are sufficiently distinct that they cannot be assigned to any of the species or other morphs recognized here. Nor are they closely comparable with other maxillary specimens known to us from Upper Cretaceous deposits elsewhere in the Western Interior.

\section{Anura indeterminate morph 3}

(Text-fig. 10)

Material and occurrences: Maxillae from Dinosaur Park Formation and Oldman Formation, Alberta, Canada; maxillae from Judith River Formation, Montana, USA; maxillae from Kaiparowits Formation, Utah, USA (Appendix 2).

D e s c ription: An assortment of fragmentary, toothed maxillae from various localities are notable for having labial surfaces that range from smooth to weakly ornamented. As shown by the six examples depicted in Text-fig. 10, these specimens preserve various portions of the maxilla and represent a size range of individuals.

AMNH FARB 8462 (Text-fig. 10a, b) is the anterior portion of a moderate-sized, left maxilla that is broken posteriorly in front of the processus palatinus and is missing the dorsal part of the lamina anterior. Despite being incomplete, the preorbital region clearly was at least moderately tall and the anterior edge of its lamina anterior is bluntly rounded in lingual or labial outline, without any indication of a distinct, anteriorly-directed rostellum (cf. Text-figs $5 \mathrm{~g}, \mathrm{~h}$ and $8 \mathrm{a}, \mathrm{b}$ ). The preserved portion of the lamina horizontalis, which probably lies below where the processus palatinus would have been located, is a shallow and lingually expanded shelf. In contrast to the dorsal curvature typical for maxillae of our unnamed genus and species II (cf. Text-fig. 7), the lingual margin of the lamina horizontalis in AMNH FARB 8462 curls ventrally. The preserved tooth bases demonstrate that the teeth were relatively large and moderately spaced. In contrast to the other five figured examples, the labial surface of FARB AMNH FARB 8462 is smooth. The distinctiveness of this specimen was recognized over 40 years ago, when Sahni (1972b: 347 and fig. 7N, O) erected it as the exemplar for his "Discoglossid B", which he characterized as "large frog with smooth maxilla".

A second maxilla, AMNH FARB 33040 (Text-fig. 10c, d) from the same locality (Clambank Hollow, Judith River Formation), exhibits a more roughened labial texture. This right maxilla is from a larger individual and it is more robustly built. It preserves the area bearing the processus pterygoideus and adjacent portions of the bone. Despite the fragmentary nature of this specimen, it is evident that the margo orbitalis (anteriorly incomplete) is deeply concave, the processus zygomatico-maxillaris (broken posteriorly) is considerably higher than the suborbital region (i.e., preserved height of process at least twice the vertical depth of the bone below the lowest point along the margo orbitalis), the processus pterygoideus (broken lingually) is prominent and projected lingually, the lamina horizontalis is relatively deep, moderately wide lingually, and has a shallowly convex lingual face, and the tooth row (broken posteriorly) extended posteriorly well past the level of the processus pterygoideus.

Examples of micro pitted labial texture are seen in two fragmentary, left maxillae from different localities: TMP 1987.029.0085 (Text-fig. 10e, f), from Dinosaur Provincial Park (Oldman Formation), preserves the portion bearing the processus palatinus and is from a moderate-sized individual, whereas AMNH FARB 33046 (Text-fig. 10g, h), from Clambank Hollow (Judith River Formation), is from a much larger individual and preserves the region bearing the broken base of a large processus pterygoideus. The labial surface in both specimens has a roughened texture similar to the above-described AMNH FARB 33040, but additionally is perforated by tiny pits and a few narrow, short, and shallow grooves. Pits are sparsely scattered and mostly limited to the more dorsal portion of TMP 1987.029.0085, but are more densely packed and broadly distributed across the pars facialis portion on AMNH FARB 33046 (cf. Text-fig. 10e versus g). In neither specimen are the pits enclosed by distinct ridges; instead, they are perforations in the surface of the bone. 


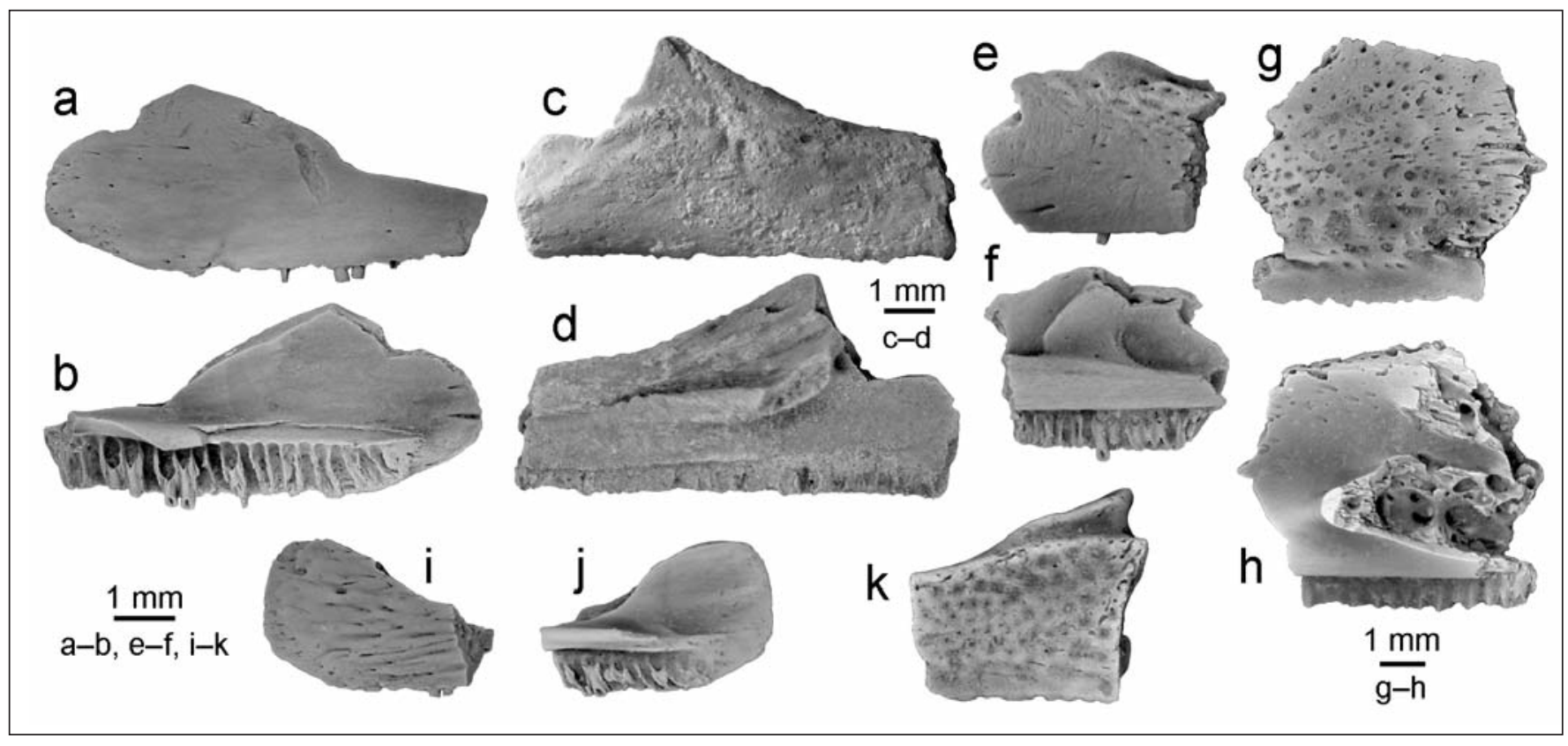

Text-fig. 10. Maxillae of Anura indeterminate morph 3 from the middle - late Campanian (Judithian) of Alberta, Canada and Montana, USA. All images are photographs and depict specimens lightly dusted with ammonium chloride to enhance details and texture. Images at different magnifications; see corresponding scale bars. a, b - incomplete left maxilla, AMNH FARB 8462, example of maxilla with smooth labial surface, in labial (a) and lingual (b) views, from Judith River Formation, Clambank Hollow, Montana. c, d - incomplete right maxilla, AMNH FARB 33040, example of maxilla with slightly roughened labial surface, in labial (c) and lingual (d) views, from Judith River Formation, Clambank Hollow, Montana. e, f - incomplete left maxilla, TMP 1987.029.0085, example of maxilla with tiny, scattered pits and some narrow, short grooves across labial surface, in labial (e) and lingual (f) views, from Oldman Formation, TMP locality L0409, Dinosaur Provincial Park, Alberta. g, h - incomplete left maxilla, AMNH FARB 33046, example of maxilla with more dense arrangement of tiny pits across labial surface, in labial (g) and lingual (h) views, from Judith River Formation, Clambank Hollow, Montana. i, j - incomplete left maxilla, UALVP 40218, example of maxilla with narrow, shallow grooves across labial surface, in labial (i) and lingual (j) views, from Dinosaur Park Formation, Irvine locality, Alberta. $k$ - incomplete right maxilla, AMNH FARB 33041, example of maxilla with shallow, somewhat polygonal divots across labial surface, in labial view, from Judith River Formation, Clambank Hollow, Montana.

Several specimens emphasize small grooves or striations over pits. Examples include the anterior end of a left maxilla (UALVP 40218: Text-fig. 10i, j) from the Dinosaur Park Formation and two previously reported, fragmentary maxillae from the Kaiparowits Formation, one preserving a similar portion of the bone and one preserving the portion bearing the processus pterygoideus (see Roček et al. 2010: fig. $15 \mathrm{Ao}$ and $\mathrm{n}$, respectively). These three specimens are from smaller-sized individuals. In each, the labial surface is indented by shallow, narrow grooves or striations of varying lengths typically arranged subparallel to one another. As with the micro pitted maxillae, the grooves are not bordered by raised ridges.

The final labial pattern is exhibited by AMNH FARB 33041 (Text-fig. 10k). This is a moderate-sized, right maxilla from Clambank Hollow (Judith River Formation) that preserves the portion bearing the processus palatinus. Its labial surface is shallowly indented by polygonal divots that are closely spaced, moderate in width, and have shallowly concave bottoms. As with the micro pitted and grooved examples reported above, these divots are simply indentations in the labial surface and are not bordered by raised ridges.

Remarks: Maxillae assigned to our morph 3 are broadly similar only in bearing teeth and in having labial surfaces that range from smooth to weakly ornamented. Differences in their labial surfaces, combined with absolute sizes and details of lingual structures (especially the form of the lamina horizontalis) suggest that multiple species are represented. That possibility is difficult to substantiate, because the available specimens are few in number and fragmentary. Overlap in preserved portions among certain specimens is helpful for showing that differences in the labial surfaces do not necessarily reflect regional differences along the bone. In the two maxillae preserving the anterior portion, the labial surface is smooth in AMNH FARB 8462 versus indented by striations on UALVP 40218 (cf. Text-fig. 10a versus i); in the two maxillae preserving the portion bearing the processus palatinus, the labial surface is perforated with tiny pits in AMNH FARB 33040 versus indented by shallow polygonal divots in AMNH FARB 33041 (cf. Text-fig. 10e versus $\mathrm{k}$ ); and in the two maxillae preserving the portion bearing the processus pterygoideus, the labial surface is roughened in AMNH FARB 33041 versus perforated with tiny pits in AMNH FARB 33046 (cf. Text-fig. 10c versus g). Based solely on similarities in their labial surfaces, certain of the specimens potentially could be from the same taxon. Specifically, the pair of micro pitted maxillae (TMP 1987.029.0085 from the Oldman Formation of Alberta and AMNH FARB 33046 from the Judith River Formation of Montana) might be from different-sized conspecifics, 
whereas maxillae indented with striations from the Dinosaur Park Formation of Alberta (UALVP 40218) and the two previously figured maxillae (Roček et al. 2010: fig. 15An, o) from the Kaiparowits Formation of Utah might be from similarly-sized conspecifics. Alternatively, those resemblances might simply be convergences.

None of the morph 3 specimens resemble other Judithian maxillae that we assign to species or to the other two morphs recognized in our review. Some of those differences are obvious: the presence of teeth differentiates morph 3 maxillae from the edentulous species Tyrrellbatrachus brinkmani and Theatonius n. sp., whereas the unornamented to weakly ornamented labial surfaces of morph 3 maxillae differentiate them from the strongly ornamented maxillae of Scotiophryne pustulosa, Hensonbatrachus kermiti, our unnamed genus and species I, morph 1 maxillae, and one (UALVP 40191) of our morph 2 maxillae. As for the remainder, differences in absolute size and the curvature of the lingual edge of the lamina horizontalis serve to differentiate the toothed and smooth maxillae of our unnamed genus and species II (smaller size and lingual edge of lamina horizontalis curved dorsally) from AMNH FARB 8462 (larger size and lingual edge of lamina horizontalis curved ventrally). Although AMNH FARB 33041 and the second (UALVP 40192) of our morph 2 maxillae are similar in bearing teeth and having shallow polygonal depressions, differences in absolute size and relative depth of the suborbital region (AMNH FARB 33041 is bigger and has deeper suborbital region) seem to argue against those being from the same species. Looking outside the Judithian, some of the maxillae assigned to our morph 3 are reminiscent of indeterminate, toothed anuran maxillae with smooth, roughened, pitted, or striated labial surfaces reported from older and younger Cretaceous deposits in the Western Interior (e.g., Gardner 2008, Roček et al. 2010).

\section{Anura indeterminate}

R e m a r k s: As summarized in Appendix 2 (see "Other occurrences of Judithian anurans"), there are numerous examples of indeterminate or unstudied anuran bones from all 10 formations included in our survey. Some of the unstudied specimens likely pertain to taxa and morphs reported above, whereas others may represent additional taxa.

\section{Discussion}

\section{Formation-level diversities of Judithian anurans}

As documented in our survey and summarized in Table 1, Judithian (middle - late Campanian) anurans are reliably known from 10 formations in the North American Western Interior. Based largely on distinctive cranial bones, we recognize a total of six or, perhaps, seven species: three named species (Scotiophryne pustulosa, Hensonbatrachus kermiti, and Tyrrellbatrachus brinkmani); three potentially diagnosable species (Theatonius n. sp. and two unnamed new genera and species); and one potentially Scotiophryne-like species (cf. Scotiophryne sp.). On the basis of distinctive maxillae, we also recognize three broad groups of morphs, one of which (our morph 1) includes material of the kind previously considered to be from an Eopelobates-like anuran. Each of those three morphs may include multiple taxa, but that possibility cannot be verified given the limited samples of incomplete maxillae currently available for each morph.

In terms of named and potentially diagnosable species, anuran species richness recognized in our review ranges from zero to three species per formation. Named species are recognized from all except the three most poorly sampled and studied units, namely the Foremost Formation of southeastern Alberta, the Two Medicine Formation of northwestern Montana, and the Aguja Formation of southwestern Texas. A single species, Scotiophryne pustulosa, is recognized in the Mesaverde Formation of central Wyoming, the Wahweap Formation of south-central Utah, and the Fruitland Formation of northeastern New Mexico. For the Oldman Formation of southeastern Alberta, we recognize Hensonbatrachus kermiti and possibly our unnamed genus and species I; the latter occurrence is not certain, because the relevant specimens are from localities of uncertain stratigraphic positions. The most species rich anuran assemblages, each consisting of three species, are recognized from the Dinosaur Park Formation in the Dinosaur Provincial Park area and at Irvine in southeastern Alberta (H. kermiti, Tyrrellbatrachus brinkmani, and our unnamed genus and species I), the upper part of the Judith River Formation in north-central Montana (cf. Scotiophryne sp., H. kermiti, and our unnamed genus and species I), and the Kaiparowits Formation in south-central Utah (S. pustulosa, Theatonius n. sp., and our unnamed genus and species II).

Our counts for the total number of anuran species (i.e., both named and potentially diagnosable) and morphs within certain formations are broadly comparable with previous reports: Dinosaur Park Formation contains two or more species (Fox 1976b, Currie 1986, Gardner 2000) versus three species and three morphs (this study); Judith River Formation contains four species (Sahni 1968, 1972a, b) versus three species and two morphs (this study); Fruitland and Mesaverde formations both contain two species (Armstrong-Ziegler 1980 and Breithaupt 1985, respectively) versus one species (this study); and Kaiparowits Formation contains one species and 6 iliac morphs (Roček et al. 2010, 2013) versus three species and two cranial morphs (this study). Conversely, whereas we recognize only one named species and one morph in the upper part of the Wahweap Formation, Roček et al. (2013) recognized numerous iliac morphotypes from the same portion of that formation. Assuming that iliac morphotypes can be used as a proxy for taxonomic diversity, Roček et al.'s (2013) survey suggests that additional anuran taxa remain to be identified from the Wahweap Formation. We suspect that further study of those and other collections will reveal additional anuran taxa in many of the 10 formations.

Not surprisingly, there are some notable differences in formation-level inventories and taxonomic identifications between earlier reports and our review. An obvious discrepancy is that whereas an Eopelobates-like taxon previously was reported to have a wide distribution in the Judithian of the Western Interior (i.e., occurrences in the Dinosaur Park, Judith River, Mesaverde, Kaiparowits, and Fruitland formations: Fox 1976b, Armstrong-Ziegler 1978, 1980, Currie 1986, Breithaupt 1985, Bryant 1989, Hunt and Lucas 1992, 1993, Eaton et al. 1999, DeMar and Breithaupt 
Table 1. Inventory of middle - late Campanian (Judithian) anuran taxa and morphs recognized here within formations in the North American Western Interior. Formations are listed north to south. See text and Appendix 2 for details, citations, and voucher specimens.

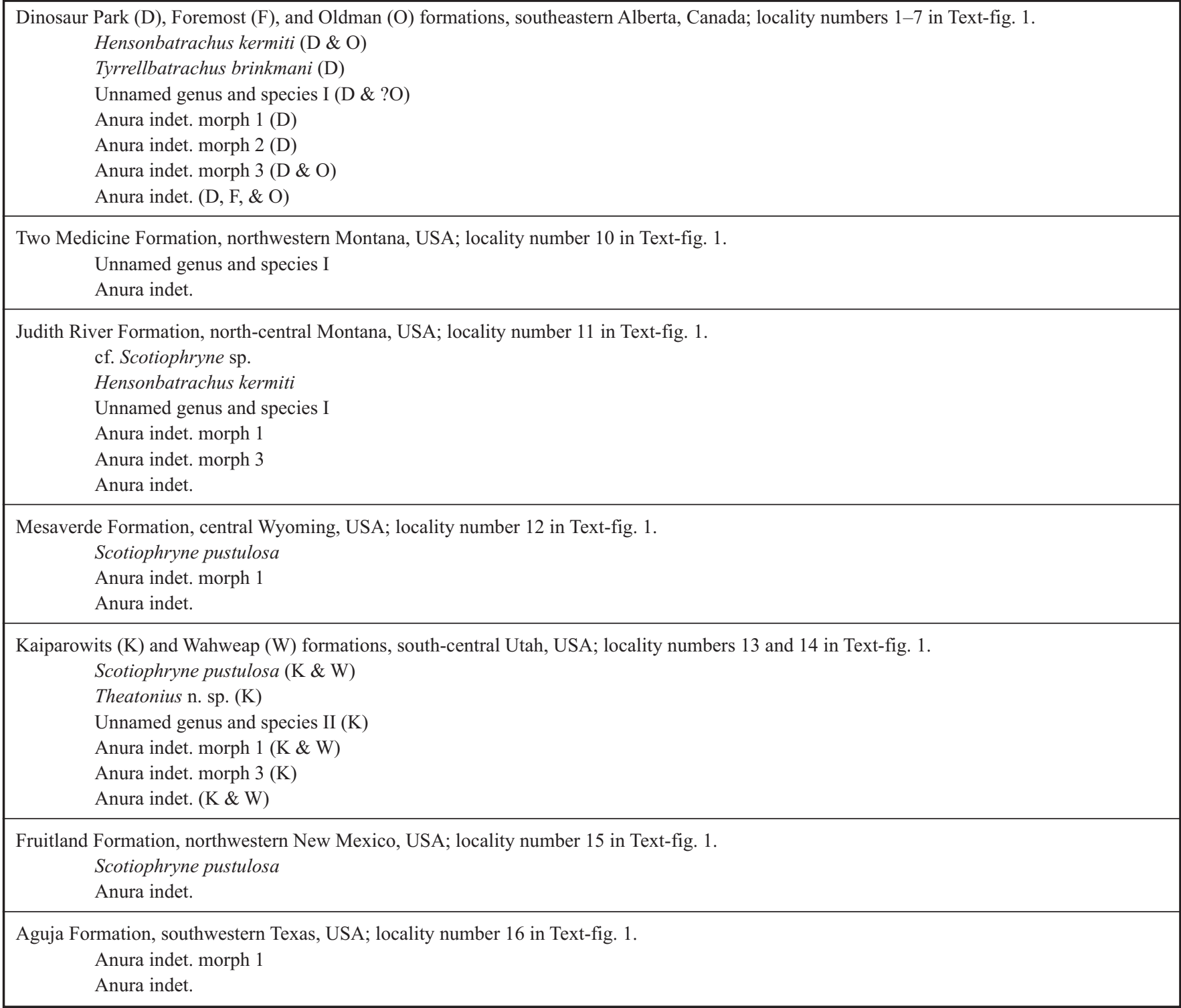

2006, 2008, Gardner and DeMar 2013), for reasons stated above and in Appendix 2, here we instead assign such specimens from the first four formations to our morph 1 and regard the sole specimen from the Fruitland Formation as being from an indeterminate anuran. The exclusion of that genus from our inventories also removes the family Pelobatidae Bonaparte, 1850 from the Judithian of the Western Interior. The only other report for Pelobatidae in the Judithian was founded on two incomplete ilia from the Judith Formation (Sahni 1968, 1972b); those relatively generalized ilia exhibit no features convincingly diagnostic for Pelobatidae or any other anuran family. As currently recognized in its strict sense (i.e., containing the Cenozoic genera Pelobates WAGLER, 1830 and Eopelobates), in North America Pelobatidae is best considered restricted to the Eocene of the western USA, where it is represented by two species of Eopelobates (see recent review by Roček et al. 2014).

Second, earlier reports of other anuran families (i.e., Ascaphidae FEJÉRVÁRY, 1923; Discoglossidae sensu lato; and
Palaeobatrachidae Cope, 1865) in the Judithian of the Western Interior are not supported by any convincingly diagnostic specimens, either reported in the literature or known to us. The Ascaphidae report was contained in preliminary faunal lists for the Dinosaur Park Formation (Fox 1976a, Currie 1986), and may have been based on generalized anuran bones that primitively resembled those of ascaphids. Reports of discoglossids senu lato in the Judithian are more widespread (e.g., Judith River Formation: Sahni 1968, 1972a, b; Dinosaur Park Formation: Fox 1976b; Mesaverde Formation: Breithaupt 1985: Fruitland Formation: Armstrong-Ziegler 1980), and were founded either on bones reminiscent of extant "discoglossids" (e.g., Discoglossus Oтtн, 1837 and Alytes WAGLER, 1830, now assigned to Alytidae Fitzinger, 1843; Bombina OKen, 1816 and Barbourula TAYLOR et NOBLE, 1924, now assigned to Bombinatoridae GRAY, 1825) or the original interpretation (see Estes 1969, Estes and Sanchiz 1982) that Scotiophryne was a discoglossid sensu lato closely related to Bombina. On the basis of generalized resemblances or unspecified features, 
Scotiophryne also has been regarded as a pelobatid (Vergnaud-Grazzini and Wenz 1975), an incertae sedis discoglossid (Sanchiz 1998), an intermediary between discoglossids sensu lato and leiopelmatids (Clarke 2007), or an alytid (Blackburn and Wake 2011). Considering that Scotiophryne is known only by isolated bones that exhibit no obvious synapomorphies for allying it with any family, the genus is best regarded as an incertae sedis anuran (Gardner 2008, Roček 2013). The claim that palaeobatrachids occur in the Judithian was based on Bryant (1989: table 2) having listed the type genus Palaeobatrachus TsCHUDI, 1838 as occurring in that interval. Bryant (1989) never provided any details to support that claim. Citing that report, Blob et al. (2001) subsequently stated that Palaeobatrachus occidentalis (for a recent critique of that generic assignment, see Wuttke et al. 2012) was present in the Judith River Formation. No Palaeobatrachus-like specimens have been reported or are known to us from any Judithian deposit. We thus disregard reports of Palaeobatrachus in the Judith River Formation and of the family in the Judithian. None of the other named or potentially diagnosable anuran taxa recognized here from the Judithian can be assigned with confidence to any family (e.g., Theatonius: Fox 1976b, Estes and Sanchiz 1982; Hensonbatrachus: Gardner and Brinkman 2015; Tyrrellbatrachus: Gardner 2015).

\section{Patterns in the Judithian anuran record}

None of the anurans recognized in our survey occurs in all ten formations. Our morph 1 has the broadest geographic distribution, occurring in seven formations from southeastern Alberta southwards into southwestern Texas. Considering that our morph 1 grouping likely contains multiple taxa, those occurrences are not particularly informative aside from demonstrating that a variety of indeterminate, toothed anurans with pit-and-ridge style cranial ornament, some of which attained moderately large body sizes (perhaps comparable to Hensonbatrachus kermiti), were broadly distributed through the Western Interior during the Judithian. A similar pattern throughout the Western Interior during much of the Late Cretaceous is suggested by morph 1-like fossils from older (Roček et al. 2010) and younger (Gardner 2008) deposits in the region.

Scotiophryne pustulosa is the most geographically and temporally broadly distributed of the anuran taxa recognized in our study, with reported occurrences in the Western Interior of USA and Canada ranging from perhaps the Aptian - Albian, but more reliably from the late Santonian to the late Maastrichtian and early Paleocene and, outside of the Western Interior, perhaps in the Campanian of both Baja California, Mexico and New Jersey, USA (e.g., Estes 1969, Estes and Sanchiz 1982, Denton and O'Neill 1998, Holman 2003, Gardner 2008, Roček et al. 2010, Gardner and DeMar 2013, Oreska et al. 2013, Roček 2013). Not surprisingly, Scotiophryne pustulosa also has the broadest geographic distribution for any Judithian anuran species. It occurs in four formations in the southern part of the Western Interior: Mesaverde Formation of Wyoming (Breithaupt 1985, DeMar and Breithaupt 2006, 2008); Kaiparowits and Wahweap formations of Utah (Roček et al. 2010, 2013); and Fruitland Formation of New Mexico (Armstrong-Ziegler 1978, 1980).
We are unaware of any specimens that support a preliminary listing by Currie (1986) of "cf. Scotiophryne" in Judithian deposits in Dinosaur Provincial Park, southeastern Alberta (that identification instead may have been based on specimens belonging to our unnamed genus and species I). However, farther to the south at Clambank Hollow, in the Judith River Formation of Montana, we identify a previously undocumented, enigmatic maxilla as cf. Scotiophryne. That specimen may represent the northernmost occurrence of Scotiophryne or of a Scotiophryne-like taxon during the Judithian.

Based on occurrences reported here, the other anuran species recognized in our study are limited to the Judithian and have more restricted geographic distributions, as follows: Hensonbatrachus kermiti in the Dinosaur Park Formation and upper part of the Oldman Formation in southeastern Alberta (Gardner and Brinkman 2015) and the upper part of the Judith River Formation in central Montana (this study); Tyrrellbatrachus brinkmani in the lower part of the Dinosaur Park Formation in southeastern Alberta (Gardner 2015); our unnamed genus and species I in the Dinosaur Park Formation and possibly the upper part of the Oldman Formation in southeastern Alberta, the middle part of the Two Medicine Formation in northwestern Montana, and the upper part of the Judith River Formation in central Montana (Gardner 2000, Gardner and DeMar 2013); and Theatonius n. sp. throughout the Kaiparowits Formation and our unnamed genus and species II in the lower part of that formation, both in south-central Utah. Theatonius n. sp. is the only example of an otherwise exclusively Lancian anuran genus first appearing (but as a different species) in the Judithian of the Western Interior. Neither of the other exclusively Lancian anuran species (Paradiscoglossus americanus and Palaeobatrachus occidentalis) nor any of the indeterminate, Lancian maxillary or iliac morphs (Gardner 2008) from the region have been recognized in geologically older Judithian localities.

Our review suggests two broad geographic anuran assemblages can be recognized in the Judithian of the Western Interior: (1) a more northern assemblage in presentday Alberta and Montana containing some combination of Hensonbatrachus kermiti, Tyrrellbatrachus brinkmani, our unnamed genus and species I, and a Scotiophryne-like species and (2) a more southern assemblage in presentday Wyoming, Utah, and New Mexico containing some combination of S. pustulosa, Theatonius n. sp., and our unnamed genus and species II. As for the three morphs we recognize, morph 1 and to a lesser extent morph 3 are present in both assemblages, whereas for morph 2 the only two recognized maxillae are both from the Irvine locality in southeastern Alberta. Latitudinal differences in anuran assemblages and the first appearance of a Lancian anuran taxon in the southern part of the Western Interior (Theatonius in Utah) are consistent with patterns reported for other latest Cretaceous non-marine vertebrates in the region, including bony fish, salamanders, turtles, squamates, and dinosaurs (e.g., Lehman 1997, Brinkman et al. 2013, Gardner et al. 2013, Hutchison et al. 2013, Nydam et al. 2013).

Prior to the Judithian, anuran assemblages in the North American Western Interior consist largely of small to moderate-sized anurans and, where upper jaws are known, 
all of those bear teeth. Roček et al.'s (2010) observation that larger sized anurans began dominating anuran assemblages in Utah in the late Campanian appears to be more geographically widespread, based on our recognition of morph 1 anurans (some of which attained larger body sizes) throughout the Western Interior and of Hensonbatrachus kermiti in southeastern Alberta and central Montana. Size estimates for $H$. kermiti based on postcranial bones suggest a maximum snout - vent length in the range of 75-115 mm (Gardner and Brinkman 2015) or about the size of many extant, Northern Hemisphere species of bufonids and ranids. Anurans of truly gigantic size, such as attained by the Maastrichtian Beelzebufo Evans, Jones et Krause, 2008 from Madagascar (estimated maximum snout - vent length of 193 mm: Evans et al. 2014), or even relatively large sizes, such as attained by the extant American bullfrog (snout - vent length up to $150 \mathrm{~mm}$ : Conant 1975), are not represented in Judithian collections. Other Judithian anurans clearly were smaller-sized. Two of those taxa - Tyrrellbatrachus brinkmani in the lower part of the Dinosaur Park Formation in southeastern Alberta and Theatonius n. sp. in the Kaiparowits Formation in south-central Utah - are the first appearances of toothless anurans in the Northern Hemisphere. That pair of likely unrelated genera document an early (minimally by Judithian) instance of independent tooth loss in anurans and they may represent the oldest record of tooth loss in non-pipoid anurans (Gardner 2015). The presence in better sampled formations of multiple anuran taxa, of various body sizes and both with and without teeth, suggests ecological and dietary partitioning among anurans was well underway by at least the Judithian in the Western Interior.

\section{Comments on some potential Judithian}

\section{and near-Judithian anuran records in North America}

There are several reports of potential Judithian or near-Judithian anuran occurrences in North American that warrant mention. The first of these is a slab described by Robison (1991) as bearing possible frog tracks and likely sourced from the Blackhawk Formation of east-central Utah, USA. Robison (1991) gave an age of only Campanian for the formation; however, more recent estimates suggest an early Campanian or pre-Judithian age for the formation (e.g., Johnson et al. 2005, Jinnah 2013: fig. 4.3). Those latter age estimates suggest that the putative frog prints from the Blackhawk Formation are comparable in age to anuran bones reported farther to the south in Utah from the lower part of the Wahweap Formation (Roček et al. 2010) and potentially from the uppermost part of the Iron Springs Formation (Eaton et al. 2014).

East of the Western Interior, the Ellisdale locality in the Marshalltown Formation of New Jersey, USA, has produced a small collection of isolated frogs bones: ilia described as being from an indeterminate discoglossid sensu lato and a pelobatid sensu lato; undescribed skull bones comparable to Scotiophryne and Theatonius; and unspecified and undescribed bones possibly belonging to a hylid (Denton and O'Neill 1998). This intriguing locality is palaeobiogeographically interesting because it is the only record for North American Late Cretaceous anurans east of the Cretaceous Interior Seaway. The Ellisdale locality is widely accepted as
Campanian in age, perhaps middle Campanian (Denton and O'Neill 2012) or equivalent to the Judithian or Aquilan (Cifelli et al. 2004, Kielan-Jaworowska et al. 2004).

Anurans have been reported from localities in two Upper Cretaceous formations in northern Mexico: the El Gallo Formation in northern Baja California (e.g., Lillegraven 1976, Estes and Sanchiz 1982, M. Montellano, pers. comm. 2015) and the Cerro del Pueblo Formation in the Parras Basin, in northeastern Mexico (Aguillon Martinez 2010). Although material from the El Gallo Formation has yet to be described, according to Estes and Sanchiz (1982) Scotiophryne pustulosa is represented in that formation by cranial and postcranial bones. Anuran material from the Cerro del Pueblo Formation consists of a few, taxonomically indeterminate postcranial bones described by Aguillon Martinez (2010). These units are palaeobiogeographically interesting because the Cerro del Pueblo Formation is the southernmost unit in the Western Interior to have produced Cretaceous anurans, whereas the El Gallo Formation lies outside of the Western Interior, to the west of the thenemerging Rocky Mountains. Current evidence suggests both units post-date the Judithian and may be equivalent to the younger "Edmontonian" NALMA (e.g., Cifelli et al. 2004, Eberth et al. 2004, Kielan-Jaworowska et al. 2004, Aguillon Martinez 2010).

\section{Concluding Remarks}

As noted in our introductory remarks, our review is not intended to be the definitive treatise on Judithian anurans. Instead, it is an overview of our current (and still limited) understanding of that portion of the anuran fossil record. It is important to emphasize that the occurrences, diversities, and patterns reported here for Judithian anurans in the North American Western Interior rely on limited information. Anuran bones vary in their abundances in vertebrate microfossil localities and almost invariably are broken; such specimens are challenging to interpret and identify. A notable exception is the collection of frog skeletons from the Two Medicine Formation - once described and analysed in detail, those should provide a wealth of information about at least one Judithian anuran taxon. For some formations only a few anuran-bearing localities are known, whether as a result of paleoenvironmental and depositional conditions, limited fieldwork, or other factors. An extreme example is provided by the Fruitland Formation, which reportedly has yielded just two fragmentary anuran maxillae from two separate localities (Armstrong-Ziegler 1980). On the other hand, certain formations contain numerous localities rich in anuran bones. Yet for the most part, any detailed understanding we have about anurans in those formations currently relies on subsets of localities that may be geographically and/or stratigraphically restricted. For example, what we know about anurans from the Judith River Formation is founded solely on Sahni's (1968, 1972b) modest-sized collection from the Clambank Hollow locality in the upper part of the formation; the dozens of other vertebrate microfossil localities mentioned by Rogers and Brady (2010) from additional horizons elsewhere in the type area have yet to be surveyed for anurans. The same is true for recently published work on 
Judithian anurans from southeastern Alberta. Although two new genera and species recently have been described from those deposits (Gardner and Brinkman 2015, Gardner 2015), those findings relied on specimens from just a few localities. Dozens more anuran-bearing localities in the region (Brinkman 1990, Eberth and Brinkman 1997, Peng et al. 2001, Brinkman et al. 2004, Frampton 2006, Cullen et al. 2016) remain to be surveyed in detail for informative anuran fossils.

Despite the above caveats and cautionary comments, our review is a useful step towards better documenting the species richness and occurrences of Judithian anuran taxa in the North American Western Interior. In contrast to the often unspoken implication that Judithian anuran assemblages were impoverished relative to younger Lancian anuran assemblages, here we have shown that at least in terms of the number of named and potentially diagnosable species (i.e., six or seven), Judithian anurans were at least as diverse as the younger Lancian assemblages. Future work on Judithian anurans (e.g., formal descriptions of significant specimens and potential new taxa recognized here; more detailed surveys of existing collections, especially those from unstudied localities; and discoveries of new localities, fossils, and taxa) will further refine data and interpretations presented here. Of particular importance will be the ability to place at least some of the Judithian taxa into a more robust phylogenetic framework - that work will have to await the description and discovery of articulated skeletal specimens and perhaps a better understanding of how features of the maxilla, ilium, and other bones commonly recovered from vertebrate microfossil localities can be used to assess relationships among anurans.

\section{Acknowledgements}

We thank Zbyněk Roček, Jiří Kvaček, and Jan Wagner for the invitation to participate in this commemorative volume celebrating the academic career of the late Professor Zdeněk V. Špinar, whose classic 1972 book "Tertiary Frogs from Central Europe" continues to be a source of information and inspiration for studies of fossil frogs. Our more modest study has relied on a number of collections made over the past half century in the Western Interior of North America. In particular, one us of (JDG) has benefited from long term access to Ashok Sahni's AMNH FARB collection made in the mid-1960s from the Judith River Formation and to collections from the Oldman and Dinosaur Park formations made in the mid-1960s to mid-1970s by Emeritus Professor Richard C. Fox (UALVP) and from the mid-1980s onwards by Don Brinkman (TMP). We thank those colleagues and collections staff at the AMNH FARB, TMP, and UALVP for that ongoing access and help with cataloguing newly "discovered" specimens in their collections. Also important have been OMNH specimens from the Kaiparowits Formation collected in the 1980s to early 1990s by field crews under RLC's supervision; that work was supported by the Office of Research Administration and Department of Zoology at the University of Oklahoma and by grants from the National Geographic Society (no. 2881-84), the U.S. National Science Foundation (BSR 8507598, 8796225,
8906992), and the Petroleum Research Fund of the American Chemical Society (no. 20311-G8). Certain of the more notable OMNH specimens were picked from washed matrix several decades later by $\mathrm{CMR}$ during his $\mathrm{PhD}$ research at Texas A\&M University, College Station, Texas, and a U.S. National Science Foundation International Postdoctoral Fellowship (No. OISE-1159038) held at the Royal Tyrrell Museum of Palaeontology. Additionally we thank Jeff Eaton (retired from Weber State University) for locality details about UMNH anuran fossils, Dennis Braman (TMP) for discussions about stratigraphy, Dave DeMar, Jr. (University of Washington) for providing an earlier version of Text-fig. 1 , and George Braybrook (now happily retired from the University of Alberta) for taking the scanning electron micrographs. Dave DeMar, Jr. and Zbyněk Roček provided constructive comments on our manuscript.

\section{References}

Aguillon Martinez, M. C. (2010): Fossil vertebrates from the Cerro del Pueblo Formation, Coahuila, Mexico, and the distribution of late Campanian (Cretaceous) terrestrial vertebrate faunas; PhD dissertation. - MS, Southern Methodist University, Dallas, Texas, USA, 135 pp. (copy in library at Royal Tyrrell Museum of Palaeontology, Drumheller, Alberta, Canada)

Armstrong-Ziegler, J. G. (1978): An aniliid snake and associated vertebrates from the Campanian of New Mexico. - Journal of Paleontology, 52(2): 480-483.

Armstrong-Ziegler, J. G. (1980): Amphibia and Reptilia from the Campanian of New Mexico. - Fieldiana Geology, New Series, 4: 1-39.

Blackburn, D. C., Wake, D. B. (2011): Class Amphibia Gray, 1825. - In: Zhang, Z.-Q. (ed.), Animal biodiversity: An outline of higher-level classification and survey of taxonomic richness. Zootaxa, 3148: 39-55.

Blob, R. W., Carrano, M. T., Rogers, R. R., Forster, C. A., Espinoza, N. R. (2001): A new fossil frog from the Upper Cretaceous Judith River Formation of Montana. - Journal of Vertebrate Paleontology, 21(1): 190-194. http://dx.doi.org/10.1671/0272-4634(2001)021[0190:AN FFFT]2.0.CO;2

Bonaparte, C. L. J. L. (1850): Conspectus Systematum. Herpetologiae et Amphibiologiae. Editio Altera Reformata. - E. J. Brill, Lugduni Batavorum [= Leiden], 1 p.

Breithaupt, B. H. (1982): Paleontology and paleoecology of the Lance Formation (Maastrichtian), east flank of Rock Springs Uplift, Sweetwater County, Wyoming. - University of Wyoming Contributions to Geology, 21(2): 123-151.

Breithaupt, B. H. (1985): Nonmammalian vertebrate faunas from the Late Cretaceous of Wyoming. - In: Wyoming Geological Association, Thirty-sixth Annual Field Conference Guidebook, pp. 159-175.

Brinkman, D. B. (1990): Paleoecology of the Judith River Formation (Campanian) of Dinosaur Provincial Park, Alberta, Canada: evidence from vertebrate microfossil localities. - Palaeogeography, Palaeoclimatology, Palaeoecology, 78(1): 37-54.

http://dx.doi.org/10.1016/0031-0182(90)90203-J 
Brinkman, D. B., Newbrey, M. G., Neuman, A. G., Eaton, J. G. (2013): Freshwater osteichthyes from the Cenomanian to late Campanian of Grand Staircase-Escalante National Monument, Utah. - In: Titus, A. L., Loewen, M. A. (eds), At the Top of the Grand Staircase: The Late Cretaceous of Southern Utah, Indiana University Press, Bloomington, pp. 195-236.

Brinkman, D. B., Russell, A. P., Eberth, D. A., Peng, J. (2004): Vertebrate palaeocommunities of the lower Judith River Group (Campanian) of southeastern Alberta, Canada, as interpreted from vertebrate microfossil assemblages. - Palaeogeography, Palaeoclimatology, Palaeoecology, 213(3-4): 295-313.

http://dx.doi.org/10.1016/S0031-0182(04)00386-4

Bryant, L. J. (1989): Non-dinosaurian lower vertebrates across the Cretaceous-Tertiary boundary in northeastern Montana. - University of California Publications in Geological Sciences, 134: 1-107.

Cifelli, R. L., Eberle, J. J., Lofgren, D. L., Lillegraven, J. A., Clemens, W. A. (2004): Mammalian biochronology of the latest Cretaceous. - In: Woodburne, M. O. (ed.), Late Cretaceous and Cenozoic Mammals of North America: Biostratigraphy and Geochronology, Columbia University Press, New York, pp. 21-42.

Cifelli, R. L., Nydam, R. L., Gardner, J. D., Weil, A., Eaton, J. G., Kirkland, J. I., Madsen, S. K. (1999): Medial Cretaceous vertebrates from the Cedar Mountain Formation, Emery County, Utah: the Mussentuchit Local Fauna. - In: Gillette, D. D. (ed.), Vertebrate Paleontology in Utah. Utah Geological Survey Miscellaneous Publication, 99-1: 219-242.

Clarke, B. T. (2007). Comparative morphology and amphibian taxonomy: an example from the osteology of discoglossoid frogs. - In: Heatwole, H., Tyler, M. J. (eds), Amphibian Biology, Volume 7, Systematics, Surrey Beatty \& Sons, Chipping Norton, pp. 2465-2612.

Conant, R. (1975): A Field Guide to Reptiles and Amphibians of Eastern and Central North America, Second Edition (The Peterson Field Guide Series 12). - Houghton Mifflin, Boston, 429 pp.

Cope, E. D. (1865): Sketch of the primary groups of Batrachia Salientia. - Natural History Review, 5(1): 97-120.

Cullen, T. M., Fanti, F., Capobianco, C., Ryan, M. J., Evans. D. C. (2016): A vertebrate microsite from a marineterrestrial transition in the Foremost Formation (Campanian) of Alberta, Canada, and the use of faunal assemblage data as a paleoenvironmental indicator. Palaeogeography, Palaeoclimatology, Palaeoecology, 444: 101-114.

http://dx.doi.org/10.1016/j.palaeo.2015.12.015

Currie, P. J. (1986): Dinosaur fauna. - In: Naylor, B. G. (ed.), Dinosaur Systematics Symposium Field Trip Guidebook to Dinosaur Provincial Park, 2 June 1986, Tyrrell Museum of Palaeontology, Drumheller, Alberta, pp. 17-23.

DeMar, D. G., Jr., Breithaupt, B. H. (2006): The nonmammalian vertebrate microfossil assemblages of the Mesaverde Formation (Upper Cretaceous, Campanian) of the Wind River and Bighorn basins, Wyoming. - New Mexico Museum of Natural History Science Bulletin, 35: 33-53.
DeMar, D. G., Jr., Breithaupt, B. H. (2008): Terrestrial and aquatic vertebrate paleocommunities of the Mesaverde Formation (Upper Cretaceous, Campanian) of the Wind River and Bighorn basins, Wyoming. - In: Sankey, J. T., Baszio, B. (eds), Vertebrate Microfossil Assemblages: Their Role in Paleoecology and Paleobiogeography, Indiana University Press, Bloomington, pp. 78-103.

Denton, R. K., Jr., O’Neill, R. C. (1998): Parrisia neocesariensis, a new batrachosauroidid salamander and other amphibians from the Campanian of eastern North America. - Journal of Vertebrate Paleontology, 18(3): 484-494. http://dx.doi.org/10.1080/02724634.1998.10011076

Denton, R. K., Jr., O’Neill, R. C. (2012): Exploring the “lost continent" of Appalachia - the Ellisdalean land fauna and its implications for Late Cretaceous biogeography. - In: Program and Abstracts, $72^{\text {nd }}$ Annual Meeting, Society of Vertebrate Paleontology, p. 86.

Duellman, W. E., Trueb, L. (1986): Biology of Amphibians. - McGraw-Hill, New York, 670 pp.

Eaton, J. G, Cifelli, R. L. (1988): Preliminary report on Late Cretaceous mammals of the Kaiparowits Plateau, southern Utah. - University of Wyoming Contributions to Geology, 26(1): 45-55.

Eaton, J. G., Cifelli, R. L., Hutchison, J. H., Kirkland, J. I., Parrish, J. M. (1999): Cretaceous vertebrate faunas from the Kaiparowits Plateau, south-central Utah. - In: Gillette, D. D. (ed.), Vertebrate Paleontology in Utah, Utah Geological Survey Miscellaneous Publication, 99-1: 345-353.

Eaton, J. G., Gardner, J. D., Kirkland, J. I., Brinkman, D. B., Nydam, R. L. (2014): Vertebrates of the Iron Springs Formation, Upper Cretaceous, southwestern Utah. - In: MacLean, J. S., Biek, R. F., Huntoon, J. E. (eds), Geology of Utah's Far South, Utah Geological Association Publication, 43: 523-555.

Eberth, D. A. (1990): Stratigraphy and sedimentology of vertebrate microfossil sites in the uppermost Judith River Formation (Campanian), Dinosaur Provincial Park, Alberta, Canada. - Palaeogeography, Palaeoclimatology, Palaeoecology, 78(1): 1-36. http://dx.doi.org/10.1016/0031-0182(90)90202-I

Eberth, D. A. (2005): The geology. - In: Currie, P. C., Koppelhus, E. B. (eds), Dinosaur Provincial Park: A Spectacular Ancient Ecosystem Revealed, Indiana University Press, Bloomington, pp. 54-82.

Eberth, D. A., Braman, D. R., Tokaryk, T. T. (1990): Stratigraphy, sedimentology and vertebrate paleontology of the Judith River Formation (Campanian) near Muddy Lake, west-central Saskatchewan. - Bulletin of Canadian Petroleum Geology, 38(4): 387-406.

Eberth, D. A., Brinkman, D. B. (1997): Paleoecology of an estuarine, incised-valley fill in the Dinosaur Park Formation (Judith River Group, Upper Cretaceous) of southern Alberta, Canada. - Palaios, 12(1): 43-58. http://dx.doi.org/10.2307/3515293

Eberth, D. A., Currie, P. J., Brinkman, D. B., Ryan, M. J., Braman, D. R., Gardner, J. D., Lam, V. D., Spivak, D. N., Neuman, A. G. (2001): Alberta's dinosaurs and other fossil vertebrates: Judith River and Edmonton groups (Campanian-Maastrichtian). - In: Hill, C. L. (ed.), 
Mesozoic and Cenozoic Paleontology in the Western Plains and Rocky Mountains. Guidebook for the Field Trips of the Society of Vertebrate Paleontology $61^{\text {st }}$ Annual Meeting. Museum of the Rockies Occasional Paper, 3: 47-75.

Eberth, D. A., Delgado-de Jesus, C. R., Lerbekmo, J. F., Brinkman, D. B., Rodriguez-de la Rosa, R. A., Sampson, S. D. (2004): Cerro del Pueblo Formation (Difunta Group, Upper Cretaceous), Parras Basin, southern Coahuila, Mexico: reference sections, age, and correlation. - Revista Mexicana de Ciencias Geológicas, 21(3): 335-352.

Estes, R. (1964): Fossil vertebrates from the Late Cretaceous Lance Formation, eastern Wyoming. - University of California Publications in Geological Science, 49: 1-180 +5 plates.

Estes, R. (1969): A new fossil discoglossid frog from Montana and Wyoming. - Breviora, 328: 1-7.

Estes, R. (1970): New fossil pelobatid frogs and a review of the genus Eopelobates. - Bulletin of the Museum of Comparative Zoology, 139(6): 293-339.

Estes, R., Berberian, P., Meszoely, C. A. M. (1969): Lower vertebrates from the Late Cretaceous Hell Creek Formation, McCone County, Montana. - Breviora, 337: $1-33$.

Estes, R., Sanchiz, B. (1982): New discoglossid and palaeobatrachid frogs from the Late Cretaceous of Wyoming and Montana, and a review of other frogs from the Lance and Hell Creek formations. - Journal of Vertebrate Paleontology, 2(1): 9-20. http://dx.doi.org/10.1080/02724634.1982.10011914

Evans, S. E., Groenke, J. R., Jones, M. E. H., Turner, A. H., Krause, D. W. (2014). New material of Beelzebufo, a hyperossified frog (Amphibia: Anura) from the Late Cretaceous of Madagascar. - PLoS ONE, 9(1): e87236. http://dx.doi.org/10.1371/journal.pone.0087236

Evans, S. E., Jones, M. E. H., Krause, D. W. (2008): A giant frog with South American affinities from the Late Cretaceous of Madagascar. - Proceedings of the National Academy of Sciences, 105(8): 2951-2956. http://dx.doi.org/10.1073/pnas.0707599105

Fejérváry, G. J. (1923): Ascaphidae, a new family of the tailless batrachians. - Annales Historico-Naturales Musei Nationalis Hungarici, 20: 178-181.

Fischer [de Waldheim], G. (1813): Zoognosia Tabulis Synopticis Illustrata, in Usum Praelectionum Academiae Imperialis Medico-Chirurgicae Mosquensis Edita. $3^{\text {rd }}$ edition. Volume 1. - Nicolai Sergeidis Vsevolzsky, Moscow, $465 \mathrm{pp}$.

Fitzinger, L. J. F. J. (1843): Systema Reptilium. Fasciculus Primus. - Braumüller et Seidel, Wien, 106 pp.

Fox, R.C. (1976a): Upper Cretaceous and Paleocene vertebrate paleontology in Alberta. - Geological Association of Canada, Mineralogical Association of Canada, and Edmonton Geological Society Annual Meeting, Field Trip A-6 Guidebook, 25 pp. + 1 fig.

Fox, R. C. (1976b): An edentulous frog (Theatonius lancensis, new genus and species) from the Upper Cretaceous Lance Formation of Wyoming. - Canadian Journal of Earth Sciences, 13(10):1486-1490.

http://dx.doi.org/10.1139/e76-154
Frampton, E. K. (2006): Taphonomy and palaeoecology of mixed invertebrate-vertebrate fossil assemblage in the Foremost Formation (Cretaceous, Campanian), Milk River Valley, Alberta; MSc thesis. - MS, University of Calgary, Calgary, Canada, 294 pp. (copy in library at Royal Tyrrell Museum of Palaeontology, Drumheller, Alberta, Canada)

Frost, D. R., Grant, T., Faivovich, J., Bain, R. H., Haas, A., Haddad, C. F. B., de Sá, R. O., Channing, A., Wilkinson, M., Donnellan, S. C., Raxworthy, C. J., Campbell, J. A., Blotto, B. L., Moler, P. E., Drewes, R. C., Nussbaum, R. A., Lynch, J. D., Green, D. M., Wheeler, W. C. (2006): The amphibian tree of life. - Bulletin of the American Museum of Natural History, 297: 1-370. http://dx.doi.org/10.1206/0003-0090(2006)297 [0001:TATOL]2.0.CO;2

Gardner, J. D. (2000): Systematics of albanerpetontids and other lissamphibians from the Late Cretaceous of western North America; PhD Dissertation. - MS, University of Alberta, Edmonton, Canada, 577 pp. (copy in library at Royal Tyrrell Museum of Palaeontology, Drumheller, Alberta, Canada)

Gardner, J. D. (2005): Lissamphibians. - In: Currie, P. C., Koppelhus, E. B. (eds), Dinosaur Provincial Park: A Spectacular Ancient Ecosystem Revealed, Indiana University Press, Bloomington, pp. 186-201.

Gardner, J. D. (2008): New information on frogs (Lissamphibia: Anura) from the Lance Formation (late Maastrichtian) and Bug Creek Anthills (late Maastrichtian and early Paleoecene), Hell Creek Formation, USA. - In: Sankey, J. T., Baszio, B. (eds), Vertebrate Microfossil Assemblages: Their Role in Paleoecology and Paleobiogeography, Indiana University Press, Bloomington, pp. 219-249.

Gardner, J. D. (2015): An edentulous frog (Lissamphibia; Anura) from the Upper Cretaceous (Campanian) Dinosaur Park Formation of southeastern Alberta, Canada. Canadian Journal of Earth Sciences, 52(8): 569-580. http://dx.doi.org/10.1139/cjes-2014-0176

Gardner, J. D., Brinkman, D. B. (2015): A new frog (Lissamphibia, Anura) from the Late Cretaceous of Alberta, Canada. - In: Bininda-Emonds, O. R. P., Powell, G. L., Jamniczky, H. A., Bauer, A. M., Theodor, J. (eds), All Animals are Interesting: A Festschrift in Honour of Anthony P. Russell, BIS Verlag, Oldenberg (Germany), pp. 35-105.

Gardner, J. D., DeMar, D. G., Jr. (2013): Mesozoic and Paleocene lissamphibian assemblages of North America: a comprehensive review. - Palaeobiodiversity and Palaeoenvironments, 93(4): 459-515. http://dx.doi.org/10.1007/s12549-013-0130-z

Gardner, J. D., Eaton, J. G., Cifelli, R. L. (2013): Preliminary report on salamanders (Lissamphibia; Caudata) from the Late Cretaceous (late Cenomanian-late Campanian) of southern Utah, U.S.A. - In: Titus, A. L., Loewen, M. A. (eds), At the Top of the Grand Staircase: The Late Cretaceous of Southern Utah, Indiana University Press, Bloomington, pp. 237-272.

Gardner, J. D., Roček, Z., Přikryl, T., Eaton, J. G., Blob, R. W., Sankey, J. T. (2010): Comparative morphology of the ilium of anurans and urodeles (Lissamphibia) and 
a re-assessment of the anuran affinities of Nezpercius dodsoni Blob et al., 2001. - Journal of Vertebrate Paleontology, 30(6): 1684-1696.

http://dx.doi.org/10.1080/02724634.2010.521605

Gray, J. E. (1825): A synopsis of the genera of reptiles and Amphibia, with a description of some new species. Annals of Philosophy, New Series, 10: 193-217.

Günther, A. C. L. G. (1858): On the systematic arrangement of the tailless batrachians and the structure of Rhinophrynus dorsalis. - Proceedings of the Zoological Society of London, 26(1): 339-352. http://dx.doi.org/10.1111/j.1469-7998.1858.tb06387.x

Haeckel, E. (1866): Generelle Morphologie der Organismen. Allgemeine Grundzüge der organischen FormenWissenschaft, mechanisch begründet durch die von Charles Darwin reformirte Descendenz-Theorie, Vol. 2. - Georg Reimer, Berlin, 462 pp. +8 plates. http://dx.doi.org/10.1515/9783110848281

Holman, J. A. (2003): Fossil Frogs and Toads of North America. - Indiana University Press, Bloomington, 246 pp.

Hunt, A. P., Lucas, S. G. (1992): Stratigraphy, paleontology and age of the Fruitland and Kirtland Formations (Upper Cretaceous), San Juan Basin, New Mexico. - In: Lucas, S. G., Kues, B. S., Williamson, T. E., Hunt, A. P. (eds), San Juan Basin IV. New Mexico Geological Society $43^{\text {rd }}$ Annual Fall Field Conference Guidebook, pp. 217-239.

Hunt, A. P., Lucas, S. G. (1993): Cretaceous vertebrates of New Mexico. - New Mexico Museum of Natural History and Science Bulletin, 2: 77-81.

Hutchison, J. H., Knell, M. J., Brinkman, D. B. (2013): Turtles from the Kaiparowits Formation, Utah. - In: Titus, A. L., Loewen, M. A. (eds), At the Top of the Grand Staircase: The Late Cretaceous of Southern Utah, Indiana University Press, Bloomington, pp. 295-318.

Jinnah, Z. (2013): Tectonic and sedimentary controls, age, and correlation of the upper Cretaceous Wahweap Formation, southern Utah. - In: Titus, A. L., Loewen, M. A. (eds), At the Top of the Grand Staircase: The Late Cretaceous of Southern Utah, Indiana University Press, Bloomington, pp. 57-73

Johnson, K. A., Culver, S. J., Kamola, D. L. (2005): Marginal marine foraminifera of the Blackhawk Formation (Late Cretaceous, Utah). - Journal of Foraminiferal Research, 35(1): 50-64. http://dx.doi.org/10.2113/35.1.50

Kielan-Jaworowska, Z., Cifelli, R. L., Luo, Z.-X. (2004): Mammals from the Age of Dinosaurs: Origins, Evolution, and Structure. - Columbia University Press, New York, $630 \mathrm{pp}$.

Laurenti, J. N. (1768). Specimen Medicum, Exhibens Synopsin Reptilium Emendatum cum Experimentis Circa Venena et Antidota Reptilium Austriacorum. - Joannis Thomae Nobilis de Trattnern, Vienna, 214 pp. +5 plates.

Lehman, T. M. (1997): Late Campanian dinosaur biogeography in the Western Interior of North America. - In: Wolberg, D. A., Stump, E., Rosenberg, G. D. (eds), Dinofest International: Proceedings of a Symposium Sponsored by Arizona State University, a publication of The Academy of Natural Sciences, pp. 223-240.

Lillegraven, J. A. (1976): A new genus of therian mammal from the Late Cretaceous "El Gallo Formation," Baja
California, Mexico. - Journal of Paleontology, 50(3): 437-443.

Mercier, G., DeMar, D. G., Jr., Wilson, G. P. (2014): Frogs and toads (Lissamphibia, Anura) during the end-Cretaceous mass extinction: evidence from the fossil record of northeastern Montana. - In: Program and Abstracts, $74^{\text {th }}$ Annual Meeting, Society of Vertebrate Paleontology, p. 187.

Nydam, R. L., Rowe, T. B., Cifelli, R. L. (2013): Lizards and snakes of the Terlingua Local Fauna (late Campanian), Aguja Formation, Texas, with comments on the distribution of paracontemporaneous squamates throughout the Western Interior of North America. - Journal of Vertebrate Paleontology, 33(5): 1081-1099. http://dx.doi.org/10.1080/02724634.2013.760467

Oken, L. (1816): Lehrbuch der Naturgeschichte. Vol. 3. Zoologie. Abtheilung 2. Atlas. - C. H. Reclam, Leipzig, $1270 \mathrm{pp}$.

Otth, A. (1837): Beschreibung einer neuen europäischen Froschgattung, Discoglossus. - Neue Denkschriften der Allgemeinen Schweizerischen Gesellschaft für die gesammten Naturwissenschaften, 1(1): 1-8.

Oreska, M. P. J., Carrano, M. T., Dzikiewicz, K. M. (2013): Vertebrate paleontology of the Cloverly Formation (Lower Cretaceous), 1: Faunal composition, biogeographic relationships, and sampling. - Journal of Vertebrate Paleontology, 33(2): 264-292. http://dx.doi.org/10.1080/02724634.2012.717567

Parker, H. W. (1929): Two fossil frogs of the lower Miocene of Europe. - Annals and Magazine of Natural History, Series 10, 4: 270-281. http://dx.doi.org/10.1080/00222932908673051

Peng, J., Brinkman, D. B., Russell, A. P. (1995): A paleoecological study of vertebrate microfossil assemblages from the lower Judith River Group (Campanian) of southeastern Alberta, Canada. - In: Sun, A., Wang, Y. (eds), Sixth Symposium on Mesozoic Terrestrial Ecosystems and Biota, Short Papers, China Ocean Press, Beijing, pp. 185-187.

Peng, J., Russell, A. P., Brinkman, D. B. (2001): Vertebrate microsite assemblages (exclusive of mammals) from the Foremost and Oldman formations of the Judith River Group (Campanian) of southeastern Alberta: an illustrated guide. - Provincial Museum of Alberta Natural History Occasional Paper, 25: 1-54. http://dx.doi.org/10.5962/bhl.title.115853

Roberts, E. M., Sampson, S. D., Deino, A. L., Bowring, S. A., Buchwaldt, R. (2013): The Kaiparowits Formation: a remarkable record of Late Cretaceous terrestrial environments, ecosystems, and evolution in western North America. - In: Titus, A. L., Loewen, M. A. (eds), At the Top of the Grand Staircase: The Late Cretaceous of Southern Utah, Indiana University Press, Bloomington, pp. 85-106.

Robison, S. F. (1991): Bird and frog tracks from the Late Cretaceous Blackhawk Formation in east-central Utah. In: Chidsey, T. C., Jr. (ed.), Geology of East-Central Utah. Utah Geological Association Publication, 19: 325-334.

Roček, Z. (2000): Mesozoic anurans. - In: Heatwole, H., Carroll, R. L. (eds), Amphibian Biology, Volume 4: Paleontology, Surrey Beatty \& Sons, Chipping Norton, pp. 1295-1331. 
Roček, Z. (2013): Mesozoic and Tertiary Anura of Laurasia. - Palaeobiodiversity and Palaeoenvironments, 93(4): 397-439. http://dx.doi.org/10.1007/s12549-013-0131-y

Roček, Z., Eaton, J. G., Gardner, J. D., Přikryl, T. (2010): Evolution of anuran assemblages in the Late Cretaceous of Utah, USA. - Palaeobiodiversity and Palaeoenvironments, 90(4): 341-394.

http://dx.doi.org/10.1007/s12549-010-0040-2

Roček, Z., Gardner, J. D., Eaton, J. G., Přikryl, T. (2012): Similarities and differences in the ilia of Late Cretaceous anurans and urodeles. - Bulletin de la Société Géologique de France, 183(6): 529-535.

http://dx.doi.org/10.2113/gssgfbull.183.6.529

Roček, Z., Gardner, J. D., Eaton, J. G., Přikryl, T. (2013): Anuran ilia from the Upper Cretaceous of Utah diversity and stratigraphic patterns. - In: Titus, A. L., Loewen, M. A. (eds), At the Top of the Grand Staircase: The Late Cretaceous of Southern Utah, Indiana University Press, Bloomington, pp. 273-294.

Roček, Z., Rage, J.-C. (2000): Tertiary Anura of Europe, Africa, Asia, North America, and Australia. - In: Heatwole, H., Carroll, R. L. (eds), Amphibian Biology, Volume 4: Paleontology, Surrey Beatty \& Sons, Chipping Norton, pp. 1332-1387. http://dx.doi.org/10.1007/s12549-014-0169-5

Roček, Z., Wuttke, M., Gardner, J. D., Bhullar, B.-A. S. (2014): The Euro-American genus Eopelobates, and a re-definition of the family Pelobatidae (Amphibia, Anura). - Palaeobiodiversity and Palaeoenvironments, 94(4): 529-567.

Rogers, R. R, Brady, M. E. (2010): Origins of microfossil bonebeds: insights from the Upper Cretaceous Judith River Formation of north-central Montana. Paleobiology, 36(1): 80-112.

Rowe, T., Cifelli, R. L., Lehman, T. M., Weil, A. (1992): The Campanian Terlingua local fauna, with a summary of other vertebrates from the Aguja Formation, Trans-Pecos Texas. - Journal of Verterbrate Paleontology, 12(4): 472-493. http://dx.doi.org/10.1080/02724634.1992.10011475

Sahni, A. (1968): The vertebrate fauna of the Judith River Formation, Montana; PhD dissertation. - MS, University of Minnesota, Minneapolis, USA, 241 pp. +9 plates. (copy in library at Royal Tyrrell Museum of Palaeontology, Drumheller, Alberta, Canada)

Sahni, A. (1972a): Community structure of Campanian (Upper Cretaceous) vertebrates from the Judith River Formation in north central Montana. - In: Marek, L. (ed.), Proceedings of the International Paleontological Union: Evolution, Ostracoda, Paleoecology and Paleobiogeography, other subjects; International Geological Congress, XXIII Session, Czechoslovakia 1968, Wydawnictwa geologiczne (Instytut geologiczny), Warszawa, pp. 339-343.

Sahni, A. (1972b): The vertebrate fauna of the Judith River Formation, Montana. - Bulletin of the American Museum of Natural History, 147(6): 321-412.

Sampson, S. D., Loewen, M. A. (2010): Unraveling a radiation: a review of the diversity, stratigraphic distribution, biogeography, and evolution of horned dinosaurs (Ornithischia: Ceratopsidae). - In: Ryan, M. J., Chinnery-Allgeier, B. J., Eberth, D. A. (eds), New
Perspectives on Horned Dinosaurs: The Royal Tyrrell Museum Ceratopsian Symposium, Indiana University Press, Bloomington, Indiana, pp. 405-427.

Sanchiz, B. (1998): Salientia (Encyclopedia of Paleoherpetology, Part 4). - Verlag Dr. Friedrich Pfeil, München, 275 pp.

Sankey, J. T. (1998): Vertebrate paleontology and magnetostratigraphy of the upper Aguja Formation (late Campanian), Talley Mountain area, Big Bend National Park, Texas; Ph.D. dissertation. - MS, Louisiana State University and Agricultural and Mechanical College, Baton Rouge, USA, 251 pp. (copy in library at Royal Tyrrell Museum of Palaeontology, Drumheller, Alberta, Canada)

Sankey, J. T. (2006): Turtles of the upper Aguja Formation (late Campanian), Big Bend National Park, Texas. - New Mexico Museum of Natural History Science Bulletin, 35: 235-243.

Sankey, J. T. (2008): Vertebrate paleoecology from microsites, Talley Mountain, Aguja Formation (Late Cretaceous), Big Bend National park, Texas, USA. - In: Sankey, J. T., Baszio, B. (eds), Vertebrate Microfossil Assemblages: Their Role in Paleoecology and Paleobiogeography, Indiana University Press, Bloomington, pp. 61-77.

Storer, J. E. (1993): Additions to the mammalian palaeofauna of Saskatchewan. - Modern Geology, 18(4): 475-487.

Taylor, E. H., Noble, G. K. (1924): A new genus of discoglossid frogs from the Philippine Islands. American Museum Novitates, 121: 1-4.

Tokaryk, T. T. (1988): Preliminary vertebrate faunal list of the Oldman Formation, Saskatchewan. - Journal of Vertebrate Paleontology, 30(suppl. 3): 28A.

Trueb, L. (1973): Bones, frogs, and evolution. - In: Vial, J. L. (ed.), Evolutionary Biology of the Anurans: Contemporary Research on Major Problems, University of Missouri Press, Columbia, pp. 65-132.

Tschudi, J. J., von (1838): Classification der Batrachier, mit Berucksichtigung der Fossilen Thiere diesser Abtheilung der Reptilien. - Petitpierre, Neuchâtel, 99 pp. (Separatum ex Mémoires de la Société des sciences naturelles de Neuchâtel, vol. 2)

Varricchio, D. J. (2002): A new bird from the Upper Cretaceous Two Medicine Formation of Montana. Canadian Journal of Earth Sciences, 39(1): 19-26. http://dx.doi.org/10.1139/e01-057

Vergnaud-Grazzini, C., Wenz, S. (1975): Les discoglossidés du Jurassique Supérieur du Montsech (Province de Lérida, Espagne). - Annales de Paléontologie (Vertébrés), 61(1): 19-36.

Wagler, J. (1830): Natürliches System der Amphibien, mit vorangehender Classification der Säugthiere und Vögel. Ein Beitrag zur vergleichenden Zoologie. - J. G. Cotta, München, Stuttgart, and Tübingen, 354 pp.

Walker, J. D., Geissmann, J. W., Bowring, S. A., Babcock, L. E. (2013): The Geological Society of America Time Scale. - Geological Society of America Bulletin, 125: 259-272. http://dx.doi.org/10.1130/B30712.1

Weil, A. (1999): Multituberculate phylogeny and mammalian biogeography in the Late Cretaceous and earliest Paleocene Western Interior of North America; PhD 
dissertation. - MS, University of California, Berkeley, USA, 243 pp. (copy in library at Royal Tyrrell Museum of Palaeontology, Drumheller, Alberta, Canada)

Woodburne, M. O. (ed.) (2004): Late Cretaceous and Cenozoic Mammals of North America: Biostratigraphy and Geochronology. - Columbia University Press, New York, $391 \mathrm{pp}$.

Wuttke, M., Přikryl, T., Ratnikov, V. Yu., Dvořák, Z., Roček, Z. (2012): Generic diversity and distributional dynamics of the Palaeobatrachidae (Amphibia: Anura). Palaeobiodiversity and Palaeoenvironments, 92 (3): 367-395. http://dx.doi.org/10.1007/s12549-012-0071-y
Appendix 1. Institutional abbreviations.

AMNH FARB - American Museum of Natural History, Fossil Amphibians, Reptiles, and Birds collection, New York, New York, USA.

MOR - Museum of the Rockies, Montana State University, Bozeman, Montana, USA.

MNA - Museum of Northern Arizona, Flagstaff, Arizona, USA.

OMNH - Oklahoma Museum of Natural History, University of Oklahoma, Norman, Oklahoma, USA.

TMM - Texas Memorial Museum, University of Texas, Austin, Texas, USA.

TMP - Royal Tyrrell Museum of Palaeontology, Drumheller, Alberta, Canada.

UALP - University of Arizona Laboratory of Paleontology, Tucson, Arizona, USA.

UALVP - University of Alberta Laboratory for Vertebrate Paleontology, Edmonton, Alberta, Canada.

UCMP - University of California Museum of Paleontology, Berkeley, California, USA.

UMNH - Utah Museum of Natural History, Salt Lake City, Utah, USA.

UW - University of Wyoming Collection of Fossil Vertebrates, Laramie, Wyoming, USA.

\section{Appendix 2.}

Annotated inventory of anuran taxa, specimens, and occurrences from the middle - late Campanian (Judithian NALMA) of the North American Western Interior. Asterisk (*) indicates specimens newly reported or identified in this review. See Appendix 1 for institutional abbreviations; additional abbreviations: BB, bonebed; loc., locality.

Scotiophryne pustulosa: Judithian occurrences consist of isolated skull bones and ilia from four formations in the Western Interior of the USA.

Mesaverde Formation, Barwin Quarry-Fales Rocks locality (UW. loc. V-81006), central Wyoming: UW 44312, maxilla; UW 34924, 44221, 44222, ilia. These undescribed specimens were listed by Gardner and DeMar (2013: on-line supplemental appendix 4) and were the basis for earlier reports (DeMar and Breithaupt 2006, 2008) of Scotiophryne $\mathrm{sp}$. in the Mesaverde Formation. The first report (Breithaupt 1985) of Scotiophryne sp. in the Mesaverde Formation was founded on unspecified specimens, likely in the AMNH FARB, UCMP, and/or UW collections.

Kaiparowits Formation, four localities, south-central Utah: 1 - UMNH loc. VP 108: UMNH VP 18437, 18446, 18447, 18451, maxillae; 2 - OMNH loc. V5: OMNH $24150 *$, bulk lot of fragmentary skull bones; 3 - OMNH loc. V9: OMNH 67093, 67105*, 67106*, maxillae; OMNH 67107*, 67108*, squamosals; OMNH 67109*, 67110*, frontoparietals; 4 - OMNH locality V61: OMNH 23959*, bulk lot of fragmentary skull bones. The four UMNH maxillae were described and most were also figured as Scotiophryne pustulosa by Roček et al. (2010), whereas only one of the OMNH specimens (maxilla OMNH 67093) previously was reported as S. pustulosa (Gardner and DeMar 2013: fig. 2o, table 4, and on-line supplemental appendix 4). 
Wahweap Formation (upper portion), two localities, south-central Utah: 1 - UMNH loc. VP 77: UMNH VP 18180, 18182, 18338, ilia; 2 - UMNH loc. VP 130: UMNH VP 18103, questionably UMNH VP 18097, ilia. All ilia were described and most were figured by Roček et al. (2010); two of the listed ilia (UMNH VP 18182, 18338) also were assigned by Roček et al. (2013: 277) to their iliac "group 1, morphotype 2".

Fruitland Formation, MNA loc. 107, northeastern New Mexico: MNA P1. 1625, maxilla. This specimen was described and figured by Armstrong-Ziegler (1980) and was the basis for including Scotiophryne pustulosa in earlier (Armstrong-Ziegler 1978) and subsequent (Hunt and Lucas 1992, 1993) faunal lists for the formation.

cf. Scotiophryne sp: Judith River Formation, Clambank Hollow, north-central Montana: AMNH FARB 33045*, maxilla. This previously unreported specimen was part of a bulk lot (AMNH FARB 8467) of eight unidentified anuran maxillae collected in the mid-1960s by Ashok Sahni for his $\mathrm{PhD}$ research, but was not mentioned in his dissertation or monograph (Sahni 1968, 1972b).

Hensonbatrachus kermiti: Thirty-three isolated bones from nine localities, Dinosaur Park and Oldman formations (Judithian), southeastern Alberta, Canada; these were included and many were figured in the type description by Gardner and Brinkman (2015). Also two newly identified maxillae from the Judith River Formation (Judithian), northcentral Montana, USA.

Dinosaur Park Formation, four localities: 1 - Irvine vertebrate microfossil locality: UALVP 40167 (holotype), 40202-40207, UALVP 40037, 40038, 40052, 40152, maxillae; UALVP 40217, premaxilla; UALVP 40171, 40172, 40211, 40212, squamosals; UALVP 40170, nasal; UALVP 40173, 40174, frontoparietals; UALVP 40175, 40213, 40214, ilia; 2 - TMP loc. L0031 (= BB 31), Dinosaur Provincial Park: TMP 1985.070.0007, maxilla; 3 - TMP loc. L0086 (= BB 86), Dinosaur Provincial Park: TMP 1986.023.0032, frontoparietal; 4 - Railway Grade locality (=TMP loc. L0408 and BB 102), west of Dinosaur Provincial Park: UALVP 40208, 40209, maxillae; TMP 1974.010.0088, ilium; UALVP 40176, humerus.

Oldman Formation, three localities: 1 - TMP loc. L0406 (= BB 100, Dinosaur Provincial Park: TMP 1986.159.0065, maxilla; 2 - TMP loc. L0409 (= BB 103), northeast of Dinosaur Provincial Park: TMP 1986.178.0014, ilium; 3 UALVP unnumbered locality along South Saskatchewan River, 8 km upstream from Sandy Point: UALVP 40168, maxilla.

Unit uncertain (either Dinosaur Park Formation or Oldman Formation), two localities: 1 - UALVP loc. BGN-2: UALVP 40215, ilium; 2 - UALVP loc. RCF-1: UALVP 40216, ilium.

Judith River Formation, Clambank Hollow, north-central Montana, USA: AMNH FARB 33042*, 33043*, maxillae. These two specimens originally were part of a bulk lot of nine maxillae (AMNH FARB 8465) labelled "Discoglossid A" collected in the mid-1960s by Ashok Sahni for his PhD research, but not reported by him (Sahni 1968, 1972b); another maxilla from that bulk lot is referable to our Anura indet. morph 1 (see account below for that morph).
Tyrrellbatrachus brinkmani: Seven maxillae from six localities, lower portion of Dinosaur Park Formation (Judithian), in or near Dinosaur Provincial Park, southeastern Alberta, Canada: 1 - TMP loc. L0404 (= BB 98): TMP 1985.066.0035 (holotype); 2 - TMP loc. L0031 (= BB 31): TMP 1986.033.0033; 3 - TMP loc. L0051 (= BB 51): TMP 1986.214.0032 and 1995.145.0090; 4 - TMP loc. L1120 (=Eric's Brother's Bonebed): TMP 1995.171.0056; 5 - TMP loc. L0086 (= BB 86): TMP 2008.004.0018; 6 - TMP loc. L0401 (= BB 104 or U-2): TMP 2014.010.0019. All seven maxillae were included and figured in the type description by Gardner (2015).

Theatonius n. sp.: Six maxillae from five localities, Kaiparowits Formation (Judithian), south-central Utah, USA: 1 - OMNH loc. V5: OMNH 67085*; 2 - OMNH loc. V6: OMNH 67082, 67083*; 3 - OMNH loc. V9: OMNH 67084*; 4 - OMNH loc. V61: OMNH 67092*; 5 - UMNH loc. VP 108: UMNH VP 19310*. Two of these specimens previously were reported: UMNH VP 19310 was briefly described and figured as an indeterminate anuran by Roček et al. (2010) and OMNH 67082 was reported as "Theatonius sp. nov." by Gardner and DeMar (2013: fig. 2o, table 4, on-line supplemental appendix 4).

Unnamed genus and species I: Isolated skull and postcranial bones and skeleton from three or four formations in Alberta, Canada, and Montana, USA.

Dinosaur Park Formation, four localities in southeastern Alberta, Canada: 1 - Irvine micovertebrate locality: UALVP 40192*, 40201*, maxillae; UALVP 40181, 40185*, 40186*, squamosals; UALVP 40180, 40193*-40195*, nasals; UALVP 40182, 40183, 40196*, 40197*, frontoparietals; possibly UALVP 40184, ilium; 2 - Railway Grade locality (= TMP loc. L0408 and BB 102), west of Dinosaur Provincial Park: UALVP 40179, 40188*-40190*, 40210*, maxillae; 3 - TMP loc. L0086 (= BB 86), Dinosaur Provincial Park: TMP 1986.010.0036*, TMP 1986.023.0016*, TMP 2008.004.0016*, maxillae; TMP 2008.004.0017*, frontoparietal; 4 - near TMP loc. L0031 (= BB 31), Dinosaur Provincial Park: TMP 1986.130.0047*, frontoparietal. A subset of the UALVP specimens previously was reported, figured, and/or listed as "Genus and Species Unnamed A" by Gardner (2000: 544547, fig. 12-4), as "New gen. and sp. A" by Gardner (2005: tables 10-1, 10-2, fig. 10-1K), and as "Anura gen. et. sp. nov. 1" by Gardner and DeMar (2013: fig. 2q, table 4, on-line supplemental appendix 4) and were the basis for including "Gen. et sp. indet. \#1" in a faunal list for the formation (Eberth et al. 2001: 58).

Unit uncertain (either Dinosaur Park Formation or Oldman Formation), two localities in southeastern Alberta, Canada: 1 - UALVP loc. DM-19: UALVP 40177, 40178, maxillae; 2 - UALVP loc. RCF-21: UALVP 40187*, squamosal. See above comments for Dinosaur Park Formation specimens.

Judith River Formation, Clambank Hollow, north-central Montana, USA: AMNH FARB 8460*, maxilla. This specimen was figured and briefly described by Sahni (1968, 1972b: 347, fig. 7L, M) as an example of his "Discoglossid C".

Two Medicine Formation, MOR loc. TM-008, northwestern Montana, USA: MOR 938, skeleton. This undescribed 
specimen was figured (prior to final preparation) and listed as “Anura gen.et. sp. nov. 1" by Gardner and DeMar (2013: fig. 2q, table 4, on-line supplemental appendix 4).

Unnamed genus and species II: Twelve maxillae from Kaiparowits Formation (Judithian), two localities in southcentral Utah, USA: 1 - OMNH loc. V6: OMNH 67095*_ 67104*; 2 - UMNH loc. VP 51: UMNH VP 13267*, 13254*. The two UMNH maxillae were described and figured as indeterminate anurans by Roček et al. (2010) and one of the OMNH specimens (OMNH 67095) previously was reported as an indeterminate anuran (Gardner and DeMar 2013: fig. $2 \mathrm{n}$, table 4 , and on-line supplemental appendix 4).

Anura indeterminate, morph 1: This grouping is used for skull bones bearing pit and ridge ornament that historically were compared to the Euro-American Eocene Pliocene pelobatid genus Eopelobates. As recommended by Roček et al. (2014) in a recent generic revision for the genus, here we refrain from using the name "Eopelobates" to identify isolated, Cretaceous skull bones. Examples are known from six formations in the Western Interior.

Dinosaur Park Formation, Irvine microvertebrate locality, southeastern Alberta, Canada: UALVP 40169*, maxilla. This specimen originally was assigned to "Genus and Species Unnamed B" in Gardner's (2000) PhD dissertation, then was excluded from the list of referred specimens when that species was formally described as Hensonbatrachus kermiti by Gardner and Brinkman (2015).

Judith River Formation, Clambank Hollow, Montana, USA: AMNH FARB 8451*, 8464*, 33044*, maxillae. All three specimens were collected in the mid-1960s by Ashok Sahni for his PhD research. Incorrectly listed as AMNH FARB 8461 (that number denotes a bulk lot of four, unpublished "Discoglossid C" maxillae), AMNH FARB 8464 was figured and briefly described by Sahni (1968, 1972b: 347, fig. 7P, Q) as an example of his "Discoglossid A". Neither of the other two specimens listed here was reported by Sahni (1968, 1972b): AMNH FARB 8451 originally was labelled as "Discoglossid C" and AMNH FARB 33044 is from a bulk lot of nine maxillae (AMNH FARB 8465) labelled "Discoglossid A" (two other maxillae from that bulk lot are referable to Hensonbatrachus kermiti; see account above for that species).

Mesaverde Formation, Barwin Quarry-Fales Rocks locality (UW. loc. V-81006), central Wyoming: UW 44274*, $44275^{*}, 44276^{*}$, maxillae. These undescribed specimens were listed as "cf. Eopelobates sp." by Gardner and DeMar (2013: on-line supplemental appendix 4) and were the basis for earlier reports (DeMar and Breithaupt 2006, 2008) of an Eopelobates-like anuran in the Mesaverde Formation. The first report (Breithaupt 1985) of "cf. Eopelobates sp." in the Mesaverde Formation was founded on unspecified specimens, likely in the AMNH FARB, UCMP, and/or UW collections.

Kaiparowits Formation, six localities, south-central Utah, USA: 1 - OMNH loc. V5: OMNH 23837, maxilla; 2 OMNH loc. V6: OMNH 67094*, maxilla; OMNH 23538*, squamosal; 3 - OMNH locality V9: OMNH 67111*, maxilla; 4 - OMNH locality V61: OMNH 23960*, maxilla; 5 UMNH loc. VP. 51: UMNH VP 13269*, maxilla; 6 - UMNH loc. VP. 108: UMNH VP $18438^{*}$, maxilla. The two UMNH maxillae were described and figured as indeterminate anurans by Roček et al. (2010) and one of the OMNH specimens (OMNH 23837) was reported as "cf. Eopelobates sp." by Gardner and DeMar (2013: fig. 2n, on-line supplemental appendix 4).

Wahweap Formation (upper portion), UMNH loc. VP 77, south-central Utah: UMNH VP 18502*, maxilla. This maxilla was described and figured as an indeterminate anuran by Roček et al. (2010).

Aguja Formation, OMNH loc. V58/TMM loc. 43057 , southwestern Texas, USA: OMNH 25243*, TMM 43057$256^{*}$, maxillae. The latter specimen was listed as "Anura indet." by Rowe et al. (1992: appendix 1).

Anura indeterminate, morph 2: Dinosaur Park Formation, Irvine microvertebrate locality, southeastern Alberta, Canada: UALVP 40191*, 40192*. The latter specimen was figured as “Anura gen. et sp. indet." by Gardner and DeMar (2013: fig. 2m).

Anura indeterminate, morph 3: Examples (all maxillae) are known from four formations.

Dinosaur Park Formation, Irvine microvertebrate locality, southeastern Alberta, Canada: UALVP 40218*, maxilla.

Oldman Formation, TMP loc. L0409 (= BB 103), Dinosaur Provincial Park, southeastern Alberta, Canada: TMP 1987.029.0085*, maxilla.

Judith River Formation, Clambank Hollow, Montana, USA: AMNH FARB 8462*, 33040*, 33041*, 33046*, maxillae. All specimens were collected in the mid-1960s by Ashok Sahni for his PhD research. AMNH FARB 8462 was figured and briefly described by Sahni (1968, 1972b: 347, fig. $7 \mathrm{~N}, \mathrm{O})$ as an example of his "Discoglossid B". The remaining specimens were not reported by Sahni (1968, 1972b); AMNH FARB 33040 and 33041 were part of a bulk lot (AMNH FARB 8463) of three maxillae labelled "Discoglossid B", whereas AMNH FARB 33046 was part of a bulk lot (AMNH FARB 8467) of eight maxillae labelled "Discoglossidae" that was not assigned by Sahni to any of his three maxillary morphs.

Kaiparowits Formation, UMNH loc. VP 56, south-central Utah, USA: UMNH VP 13338*, 13353*. The two UMNH maxillae were described and figured as indeterminate anurans by Roček et al. (2010).

Other occurrences of Judithian anurans: Additional fossil anuran bones are known from 10 Judithian formations in the Western Interior of Canada and the USA. Some of these cannot be assigned to any of the above-listed taxa or groups, whereas others have yet to be studied. For completeness, we summarize those occurrences below.

Dinosaur Park Formation, multiple localities in two areas, southeastern Alberta, Canada: 1 - Dinosaur Provincial Park area: indeterminate anurans reported at 17 of 18 sampled microfossil localities (Brinkman 1990: table 2); 2 - Onefour area: indeterminate anurans reported at seven of 14 sampled vertebrate microfossil localities (Eberth and Brinkman 1997: tables 5-7).

Dinosaur Park Formation, Muddy Lake Bonebed, westcentral Saskatchewan, Canada: unidentified anurans reported 
in conference abstract (Tokaryk et al. 1988) and faunal list (Eberth et al. 1990: table 2).

Oldman Formation, multiple localities in two areas, southeastern Alberta, Canada: 1 - Dinosaur Provincial Park area: indeterminate anurans reported at all seven sampled microfossil localities (Brinkman 1990: table 2); 2 - eastern portion of Milk River valley: indeterminate anurans reported at all 16 sampled microfossil localities (Peng et al. 2001: appendix 3; repeated by Brinkman et al. 2004: appendix A).

Unit uncertain (either Dinosaur Park Formation or Oldman Formation), Woodpile Creek, southwestern Saskatchewan, Canada: unstudied anurans were mentioned by Storer (1993).

Foremost Formation, five localities in two areas, southeastern Alberta, Canada: 1 - SPS locality along Oldman River: indeterminate anurans reported at this microfossil locality (Peng et al. 2001: appendix 3; repeated by Brinkman et al. 2004: appendix A); 2 - Pinhorn Ranch and Chin Coulee area, four microfossil localities along eastern portion and north of Milk River: indeterminate anurans reported at PHR1 and -2 localities (Peng et al. 2001: appendix 3; repeated by Brinkman et al. 2004: appendix A); eight maxillae reported at PHRN locality (Frampton 2006); one ilium reported at Phil's Knob locality (Cullen et al. 2016).

Two Medicine Formation, MOR loc. TM-088, north-central Montana, USA: undescribed, disarticulated and partially associated skeletons in MOR collections (Varrichio 2002, Gardner and DeMar 2013; Gardner, Henrici, and Varricchio work in progress).

Judith River Formation, multiple localities in Missouri River Valley, north-central Montana, USA: 1 - Clambank Hollow: additional fragmentary maxillae, plus humeri and ilia (all AMNH FARB collections) from Sahni's PhD research, some listed, figured, and briefly described in his $\mathrm{PhD}$ dissertation and monograph (Sahni 1968, 1972b); 2 - University of Chicago microfossil localities (see Rogers and Brady 2010) have yielded unstudied anuran bones (Rogers, pers. comm. 2014).

Mesaverde Formation, Barwin Quarry-Fales Rocks locality (UW. loc. V-81006), central Wyoming, USA: unstudied anuran specimens in collections of AMNH FARB, UCMP, and UW.

Kaiparowits Formation, multiple localities, south-central Utah, USA: additional bones in UMNH collections reported, described, and many figured by Roček et al. (2010) and unstudied specimens in OMNH, UMNH, and possibly MNA collections.

Wahweap Formation (upper portion), multiple localities, south-central Utah, USA: additional bones in UMNH collections reported, described, and many figured by Roček et al. (2010) and unstudied specimens in UMNH and possibly MNA collections.

Fruitland Formation, UALP loc. 75137, northeastern New Mexico, USA: UALP 75137-A, fragmentary maxilla described and figured by Armstrong-Ziegler (1980: pl. 1c-d) as "?Eopelobates sp.", but not assignable to that genus (sensu Roček et al. 2014) or to our morph 1. That specimen was the basis for "?Eopelobates sp." being included in faunal lists for the formation (Armstrong-Ziegler 1978, Hunt and Lucas 1992, 1993).

Aguja Formation, multiple localities in Big Bend National Park area, southwestern Texas, USA): 1 - OMNH loc. V58/TMM loc. 43057, Terlingua local fauna: OMNH and TMM specimens listed as "Anura indet." (Rowe et al. 1992: appendix 1); 2 - Rattlesnake Mountain, unspecified localities: unstudied anuran bones mentioned by Sankey (1998, 2006, 2008). 